\title{
U.S. stock prices and the dot.com-bubble: Can dividend policy rescue the efficient market hypothesis?*
}

\author{
Tobias Basse $^{\mathrm{a}, \mathrm{b}}$, Tony Klein ${ }^{\mathrm{c}}$, Samuel A. Vigne ${ }^{\mathrm{d}, *}$, Christoph Wegener ${ }^{\mathrm{e}}$ \\ ${ }^{a}$ Norddeutsche Landesbank Girozentrale Hannover, Germany \\ ${ }^{b}$ Touro College Berlin, Germany \\ 'Queen's Management School, Queen's University Belfast, UK \\ ${ }^{d}$ Trinity Business School, Trinity College Dublin, Ireland \\ ${ }^{e}$ Methodology Center and Institute for Economics, Leuphana University Lüneburg, Germany
}

\begin{abstract}
This paper thoroughly integrates speculative bubbles to corporate finance literature by focusing on dividend policy issues. More specifically, we examine the importance of dividend policy when testing for speculative bubbles in the S\&P 500 equity index on a data set spanning 1871 to 2014. Given the phenomenon of dividend smoothing, in particular in the U.S., we question the usefulness of observed dividend payments as fundamental factor in testing for bubbles. Circumventing dividend smoothing, we construct hypothetical dividend payouts which are based on reported corporate earnings instead. The empirical evidence presented here indeed suggests that the dividend policy of firms affects testing for speculative bubbles. While the dot.com-bubble - commonly seen as the prime example for a stock price bubble not only in the NASDAQ but also in other, broader equity indices - is detected with the observed dividend series as fundamental factor, this is not necessarily the case with our adjusted dividend time series. Some of our results argue against a speculative price bubble in the broader U.S. stock market in the late 1990s.
\end{abstract}

Keywords: Dividend Policy, Financial Bubbles, Fundamentals, Explosiveness.

JEL classification: C22 $\cdot$ C58 $\cdot$ G14 $\cdot$ G32

\footnotetext{
*Corresponding Author, eMail: vignes@tcd.ie.

*The authors would like to thank the handling editor-in-chief, Professor Bart Lambrecht, the handling associate editor, whose identity was not revealed by the Editorial Manager system, and two anonymous reviewers for their helpful comments and time during the review process.
} 


\section{Introduction}

The Present Value Model of stock prices, with the commonly used Dividend Discount Model as one example, is still considered to be one of the cornerstones of financial economics (see, for example, Blanchard \& Watson, 1982, Shiller, 2014). First and foremost, this approach is a mainstay in corporate finance theory for equity valuation. Additionally, the model is also commonly used as the theoretical foundation in the bubble testing literature (see, for example, Diba \& Grossman, 1988, West, 1988, Evans, 1991). Based on these seminal contributions to the theory of occurrences and detection of bubbles, recently published papers predominantly use recursive right-tailed unit root tests to identify rational bubbles in financial asset prices (see, for example, Phillips, Wu \& Yu, 2011, Phillips \& Yu, 2011, Phillips, Shi \& Yu, 2015, Pavlidis, Paya \& Peel, 2017). One of the most important recent contributions is the approach by Phillips, Wu \& Yu (2011), which has been very influential for numerous empirical studies as it takes the critique of Evans (1991) that conventional unit root and cointegration tests have little power for periodically collapsing bubbles, into account. Given this approach, right-tailed unit root testing has been used in different segments of global financial markets, ranging from equity markets to housing markets to commodity futures such as crude oil markets (see, for example, Homm \& Breitung, 2012, Kivedal, 2013, Engsted, Hviid \& Pedersen, 2016, Pavlidis, Paya \& Peel, 2017, 2018, Figuerola-Ferretti, McCrorie \& Paraskevopoulos, 2019).

For the existence of a rational bubble, the price needs to decouple - explosively - from the fundamental.

"A rational bubble reflects a self-confirming belief that an asset's price depends on a variable (or a combination of variables) that is intrinsically irrelevant - that is, not part of market fundamentals"-Diba \& Grossman 1988, p. 520)

The fundamental of an asset can be described as the sum of the present discounted values of expected future payoffs received from the ownership of the asset. Hence, the ex-ante specification of the fundamental affects the results of these types of bubble tests (see Pavlidis, Paya \& Peel, 2017). Traditionally, observed dividend payments are used 
as a proxy for fundamental factors in the literature, affecting the valuation of the stock market. However, the dividend policy of firms might — at least partly — decouple dividend payouts from economic fundamentals. According to the concept of dividend smoothing, managers in firms try to avoid any situation in which they are forced to sharply cut or even omit dividend payments. As a consequence, it is predicted that firms tend to follow a dividend policy that smooths dividend payouts with a certain consistency. Phrased somewhat differently, managers only raise dividends as a reaction to higher corporate earnings when they believe that an increased level of dividend payments can be sustained with a reasonable likelihood in the future. Therefore, it could be quite problematic to use dividend payments as proxy variable for the fundamental value of stocks (see Marsh \& Merton, 1986, Chen, Da \& Priestley, 2012).

"Since management's choice of dividend policy clearly affects the time-series variation in observed dividends, the development of the relation between the volatility of dividends and rational stock prices requires analysis of the linkage between the largely controllable dividend process and the largely uncontrollable process for intrinsic value."-Marsh \& Merton (1986, p. 488)

Alessandri (2006) reports that some indications for the existence of speculative bubbles disappear if dividends are replaced by a broader measure of the fundamental situation of firms 11

The main contribution of this paper is to shed light on the question whether the results of right-tailed unit root tests for the U.S. stock market remain valid when dividend policy is taken into account. This empirical study focuses on the broad S\&P 500 stock market index and does not consider the NASDAQ. Hence, we examine annual U.S. data from 1871 to 2014 - more specifically the dividend payments, corporate earnings and stock prices of the S\&P 500 equity index and its predecessors - and construct several different hypothetical dividend time series that control for the dividend policy of these

\footnotetext{
1 Alessandri (2006) uses Flow of Funds data for the United States instead of S\&P dividends. A similar idea has also been presented by Chen, Da \& Priestley (2012). Moreover, there are some earlier discussions about dividend policy issues and the rationality of the stock market that are of relevance for our paper (see Marsh \& Merton, 1986, Shiller, 1986).
} 
firms. Given that dividends are paid from earnings, all of these time series are based on corporate earnings. In short, we use different rule-based approaches to simulate possible (and therefore hypothetical) dividend payouts of firms in the S\&P 500 equity index that should be more closely related to the fundamental economic situation. For example, we control for Nixon's attempt to limit increases of dividends and the changes to the taxation of dividend payouts in 2003 (see, most importantly, Baker \& Wurgler, 2004). As a matter of fact, the question of reappearing dividends after the U.S. tax reform from 2003 (see Julio \& Ikenberry, 2004) and the effects of the results of Nixon's Committee on Interest and Dividends in the early 1970s (Baker \& Wurgler, 2004) certainly could affect the results of bubble tests which are utilizing dividend payouts as proxy variable for the underlying fundamentals. Other relevant events such as World War $1 \& 2$, hereafter WW1 \& WW2, the Gold Standard, or major recessions might also matter in this context. Recessions have strong negative effects on corporate earnings as they translate to lower economic activity and inflation and therefore, are of significant relevance to the dividend policy of firms. The monetary system also affects inflation rates. It is, for example, well documented in the literature that changes to the inflationary environment might have consequences for the dividend policy of firms, which is documented in Basse \& Reddemann (2011) and Baker \& Jabbouri (2017).

While the so-called dot.com-bubble - as most important example for a possible speculative bubble in U.S. equity markets - has certainly affected the NASDAQ, it should also have had consequences for all other equity indices in North-America. By using the observed dividend payments as fundamental factor, we confirm the results by Phillips, Shi \& Yu (2015) and Phillips \& Shi (2020) identifying the existence of stock price bubbles in the S\&P 500. However, using our hypothetical dividend payments as a proxy for the fundamental, this is not the case anymore. We still find some evidence for bubbles, but these results are significantly less striking with dividend payments which are controlled for dividend policy than for the observed dividend process in the sense that bubble periods appear to be much shorter or fully disappear (depending on the specification of the parameters). It is important to note that these results resemble the findings by Pavlidis, 
Paya \& Peel (2017) for certain parameter specifications. Pavlidis, Paya \& Peel (2017) proposed a bubble testing procedure that makes the specification of the fundamentals obsolete. Hence, this approach might be better suited to provide conclusive evidence of bubbles compared to procedures which require the specification of the fundamental (see Pavlidis, Paya \& Peel, 2018, Gronwald, 2016, Kruse \& Wegener, 2019, for the discussion on the role of the specification of the fundamental for bubble testing in the oil market.).

The paper is structured as follows. In Section 2, we examine the Present Value Model of stock prices and its extensions. Further, we review the literature on dividend policy issues and introduce the data sets examined. Methodological approaches and questions are discussed. Here, we motivate the construction of our hypothetical dividend payouts. Section 3 focuses on different bubble testing approaches and introduces the identification procedure carried out in this research. Results are presented and discussed in Section 4 with a detailed evaluation of the empirical evidence. Section 5 concludes this paper.

\section{Methodological framework}

\subsection{The present value model of stock prices}

We begin with the classical definition of the Present Value Model for share price evaluation in the context of corporate finance, which reads

$$
P_{t}=\frac{1}{1+r_{t}} \mathrm{E}_{\mathrm{t}}\left[P_{t+1}+D_{t+1}\right]
$$

where $P_{t}$ is the price of a stock under investigation, $r_{t}$ denotes the (positive) discount rate, $D_{t}$ refers to the dividend process of the respective stock, and $\mathrm{E}_{t}[\cdot]:=\mathrm{E}\left[\cdot \mid \Omega_{t}\right]$ labels conditional expectations with respect to the information set $\Omega_{t}$ available at time $t$, with $t=1, \ldots, T$. We focus on the effect of dividends and corporate earnings on bubble testing. Hence, given that we examine dividend policy issues we consider an adjusted version of Eq. (1)

$$
P_{t}=\frac{1}{1+r_{t}} \mathrm{E}_{\mathrm{t}}(P_{t+1}+\underbrace{q_{t+1} C E_{t+1}}_{D_{t+1}}) \text {, }
$$


where $C E_{t}$ denotes corporate earnings and $q_{t}$ is the dividend payout ratio. Thus, firms pursue dividend policy by setting the payout as a share of corporate earnings. By applying the law of iterated expectations to Eq. (1) up to period $l$, we obtain the following decomposition into fundamental and bubble part, which reads

$$
P_{t}=\underbrace{\sum_{i=1}^{l} \frac{1}{\left(1+r_{t}\right)^{i}} \mathrm{E}_{t}\left[q_{t+i} C E_{t+i}\right]}_{F_{t}}+\underbrace{\frac{1}{\left(1+r_{t}\right)^{l}} \mathrm{E}_{t}\left[P_{t+l}\right]}_{B_{t}},
$$

with $F_{t}$ as the fundamental and $B_{t}$ as the bubble component. If the transversality condition

$$
\lim _{l \rightarrow \infty} \mathrm{E}_{t}\left[\left(1+r_{t}\right)^{-l} P_{t+l}\right]=0
$$

holds, the price equals the fundamental component-translating to $B_{t}=0$-and the stochastic trending behavior of the price process equals the stochastic trending behavior of the fundamental - which is the dividend process. Then, the stock price should equal the sum of the discounted future expected dividend payouts. Empirical evidence suggests that in this case, the price behaves like a random walk (with drift). If Eq. (4) does not hold, the price exceeds the fundamental for $B_{t}>0$ and the price process behaves explosively as the bubble satisfies

$$
\mathrm{E}_{t}\left(B_{t+1}\right)=\left(1+r_{t}\right) B_{t}
$$

where $B_{t}$ is now a submartingale process (see Diba \& Grossman, 1988). In this case, the price process decouples from the fundamental process explosively. Therefore, the basic approach for testing bubbles by recursive right-tailed unit root tests applied to stock prices is to test against explosiveness of the (log) price-dividend ratio. Apparently, the specification of the fundamental (or dividend) process is pivotal for the bubble test results. Hence, in what follows we discuss the specification of the dividend process in the light of dividend policy.

\subsection{On dividend policy}

While there is no question that many firms regularly pay dividends, it is not clearfrom a theoretical perspective - why those firms do so (see Allen, Bernardo \& Welch, 2000, 
Bonaimé, Hankins \& Harford, 2014). In their seminal paper, Miller \& Modigliani (1961) have argued convincingly that the dividend policy of a firm under certain assumptions should be of no economic relevance to the valuation of the firm. It is reasoned that the value of a firm is only determined by its ability to generate cash flows and not by its payout policy. Phrased differently, given a certain investment policy of a firm, dividends ought to be irrelevant for investors when perfect capital markets exist and taxes are absent. Under these circumstances, an increase to dividends should simply result in lower capital gains for stockholders equalizing the received dividend. Mann (1989), for example, has summarized this idea very pointedly arguing that - in perfect capital markets with given operation policies of firms - dividend policy is merely a vehicle to package the return of a firm's cash flows to its shareholders. Consequently, the volume of dividend payments made by firm should not be of any importance for financial markets when investors do not prefer dividends to capital gains or vice versa. This important idea is commonly known as Dividend Irrelevancy Hypothesis or Dividend Irrelevance Proposition (see Handley, 2008, Guan, Li \& Ma, 2018).

However, many firms do pay dividends and also spend resources on implementing the dividend policies that they consider to be optimal in one way or another. Moreover, in many countries there is a legal environment which leads to a tax disadvantage of dividend income relative to capital gains (Baker, Farrelly \& Edelman, 1985). Consequently, the phenomenon of the so-called dividend puzzle arises (see Black, 1976, Floyd, Li \& Skinner, 2015). In summary, it can be concluded that the key question in this context is why firms allocate resources to formulate a dividend policy that is assumed to be appropriate for the management and the shareholders and - at least in some countries - even decide to pay dividends in spite of a tax disadvantage to shareholders of this payout policy.

Corporate finance theory meanwhile has developed some approaches to explain why dividends may not be irrelevant after all. Agency theory is very important in this context as outlined in Short, Zhang \& Keasey (2002) and Leary \& Michaely (2011). The relevance of agency costs for the dividend policy firms has, for example, been discussed by Alli, Khan \& Ramirez (1993) as well as Agrawal \& Jayaraman (1994). In brief, this 
theoretical framework assumes that managers of a firm do not necessarily act in the best interest of the owners of the company. In order to cope with this imbalance, the owners could have an incentive to demand dividend payments which reduce the amount of free cash flow that is available to the management of the firm. As a result of the dividend payments, the firm is forced to obtain additional funds from external sources more frequently in order to finance new investment projects. Given that the process of raising new capital requires the firm to give information to investment bankers, regulators and prospective investors paying dividends should help to handle problems with information asymmetries. In fact, any need for the disclosure of relevant additional information to the public might reduce agency costs and consequently, could help the owners of a firm to have better control over their management. In this context, it is interesting that Agrawal \& Jayaraman (1994), amongst others, have reported empirical evidence indicating that dividend payments and managerial ownership are substitute mechanisms for reducing agency costs in firms. Creditors could also matter. In fact, while firms that have issued debt (respectively their owners) may have an incentive to pay dividends their creditors should try to restrict the ability of their debtors to pay dividends (see, for example, Black, 1976 , Wald, 1999).

Following the above framework, any piece of relevant additional information that the management provides to its investors and to financial markets in general can be the key to handle principal-agent problems in firms more efficiently. In this context changes to dividend payouts might also be helpful to mitigate information asymmetries. In fact, the so-called dividend signaling theory assumes that managers can use dividend changes to signal revisions to earnings expectations to the general public (see, amongst others, Beer, 1993, Goddard, McMillan \& Wilson, 2006). However, investors could also interpret dividend cuts or omissions as negative signals that indicate future problems of the firm (see, for example, Ghosh \& Woolridge, 1989, Lie, 2005). In fact, there could be an overreaction of stock prices to dividend reductions and omissions. Empirical evidence shows that this might be the case (see, amongst others, Michaely, Thaler \& Womack, 1995. Lie, 2005). There seems to be a concern in firms that investors are reacting too 
strongly to negative signals. Historical experience shows that the sentiment of investors changes quickly and that worries about unexpected negative news in particular might lead to large price swings in the stock market. As a consequence, managers of firms could have an incentive to try to avoid the need to cut or omit dividends. Subsequently, firms should only consider to increase their dividend payouts when it can assumed with reasonable certainty that the current business environment will allow the company to maintain the higher payout level in the near future (at least without major economic shocks). Lintner (1956) has noted that managers usually are reluctant to make erratic changes to dividend payments and - as a consequence - seem to have incentives to ensure a sufficient stability of their payout policies. Therefore, firms often seem to make only minor adjustments to their dividend distributions when current corporate earnings increase. More recent empirical studies also seem to support this point of view. The findings reported by Hoang \& Hoxha (2016), for example, indicate that managers have an incentive to keep adjustments to the payouts of their firms small. According to Lintner (1956), this behavior of managers could be interpreted as a reaction to the unavoidable uncertainties with regard to future developments. Of course, corporate earnings still remain to be an important determinant for the payout policies of companies.

There is a lot of related work that is of relevance in this context. Most importantly, in order to offer a basis for the considerations of Lintner (1956) that is more strongly focused on economic theory, Acharya \& Lambrecht (2015) develop a theoretical model for income and dividend smoothing in the presence of asymmetric information. This model is based on the idea that insiders try to manage the expectations of outsiders. It predicts that the degree of smoothing should depend on the economic relevance of asymmetric information. Moreover, it is shown that - consistent with observations of Lintner (1956) the volume of dividend payouts should grow over time. In fact, the model demonstrates that the growth to dividend payments ought to be closely linked to the growth of corporate earnings. Additionally, this model also predicts that an increase to the outside ownership of firms should lead to more dividend more smoothing. Furthermore, in the context of the target adjustment payout model of Lintner (1956), Lambrecht \& Myers (2012) suggest a 
dynamic agency model in which all payout, investment, and financing decisions of a firm are made by the managers of this company who try to smooth and maximize their flow of rents by smoothing the payouts to the owners of the business enterprise. Fliers (2019) demonstrates how financial flexibility of a firm affects decisions on dividend changes and finds a nonlinear relationship.

Managers of firms only try to avoid the need to cut or even omit dividends in order not to unnecessarily irritate investors. This behavior is called dividend smoothing in the corporate finance literature (see, for example, Goddard, McMillan \& Wilson, 2006, Leary $\&$ Michaely, 2011). Empirical evidence from surveys of corporate financial managers (see, for example, Baker, Farrelly \& Edelman, 1985, Baker, Veit \& Powell, 2001) as well as from past experiences with dividend payouts employing cross sectional and time series regression techniques (see, amongst others, Dewenter \& Warther, 1998, Basse \& Reddemann, 2011) points in the direction that dividend smoothing is a phenomenon of economic relevance in the U.S.

As a consequence, the dividends actually paid by firms ought to have decoupled from corporate earnings - at least to a certain extend - due to the fact that managers try to smooth dividend payouts. Therefore, the observed dividend payout time series should understate earnings and economic activity in the corporate sector on average. This results in a situation in which realized dividend payouts would appear to systematically underestimate the fundamentally justified level of stock prices. In fact, aggregate dividends in the U.S. have been smoothed more strongly in the period after WW2 than before (see, most importantly, Leary \& Michaely, 2011, Chen, Da \& Priestley, 2012). According to Reddemann, Basse \& von der Schulenburg (2010), dividend smoothing can be interpreted as dividend signaling with some precaution. Without any doubt, the two theories both assume the existence of a strong link between dividend payments and corporate earnings. Nevertheless, Goddard, McMillan \& Wilson (2006) have made it clear that the signaling and smoothing hypotheses make diametrically different predictions with regard to the temporal relationship between dividend payments and corporate earnings.

While the first hypothesis assumes that dividends should lead corporate earnings, the 
second hypothesis forecasts that earnings should lead dividend payments. In any case, the dividend smoothing hypothesis seems to be of relevance in the U.S. Consequently, managers that try to formulate an adequate dividend policy for their firm seem to have an incentive to not immediately react to an improvement of the business environment because they want to avoid the need to cut or even omit dividend payments in more difficult times. Accepting this point of view - which at least from the perspective of the corporate finance literature should most probably not be too controversial (see, most importantly, Leary \& Michaely, 2011, Chen, Da \& Priestley, 2012) - does have consequences for the new and more recent asset price bubble literature. In fact, the practice of dividend smoothing in firms seems to question the use of dividends as fundamental factor in bubble tests because of the obvious fact that this time series should understate economic activity in the corporate sector when firms smooth their dividend payouts.

\subsection{Data and methodological issues}

We examine annual stock market data from the U.S. More specifically, we focus on the three time series: dividends per index share, earnings per index share, and stock prices of the S\&P 500 equity market index and its predecessors from 1871 to 2014. The data is obtained from Robert Shiller's web page.2 The time series under investigation are not adjusted for inflation. Using annual data helps to avoid problems due to the strong seasonal patterns in the dividend time series ${ }^{3}$ We make use of nominal data and do not calculate real prices as stock markets determine nominal equity prices and investors commonly use fundamental valuation approaches based on nominal data (e.g. $\mathrm{P} /$ E-ratios amongst others). As a consequence and from the perspective of information flows among market participants, it is consistent to focus on nominal data-especially when dividend smoothing is examined. In fact, while there is literature that analyzes the role of inflation in this context (Basse \& Reddemann, 2011, Baker \& Jabbouri, 2017), dividends are smoothed in nominal terms.

\footnotetext{
${ }^{2}$ Data is freely available from http://www.econ.yale.edu/ shiller/data.htm.

${ }^{3}$ For robustness checks, we use also the monthly price-dividend ratios by Phillips \& Shi (2020) which are available within the $\mathrm{R}$ package psymonitor.
} 
We motivate our relatively long observation period starting in 1871 with the observation of Frankfurter \& Lane (1992) who have argued that old habits of firms are important in analyzing dividend policy issues. Wilson \& Jones (2002) have discussed data problems due to biases in the early monthly S\&P historical data. This is an additional important reason to focus on annual data. Given that firms seem to smooth their dividend payments raises doubts about the ability of the dividend time series to provide adequate information about the level of economic activity and the profitability of the U.S. corporate sector (see, most importantly, Alessandri, 2006, Chen, Da \& Priestley, 2012). In fact, the dividend time series should systematically underestimate the level of stock prices when firms engage in dividend smoothing. Therefore, we construct several different hypothetical dividend time series that control for the dividend policy of the firms and that thus are better suited to be used as fundamental factors in bubble tests. Given that dividends are paid from earnings as formalized in Eq. (2), all of these constructed time series are based on corporate earnings.

It is, of course, possible that broad trends in the dividend policy of firms provide additional relevant information about the business environment and the fundamental value of firms that are included in the S\&P 500 equity market index (respectively its predecessors). As a consequence, we use a number of different rule-based approaches to simulate dividend payouts which should be more closely related to the fundamental economic situation and - at least in some cases - try to obtain additional clues about the fundamental economic environment by examining different averages of dividend payout ratios. In this context, events that could have caused structural change affecting the relevant parameters obviously is of central importance. In some cases, we also exclude some periods while calculating the average payout ratios. Given extraordinary circumstances that might create a situation where there are doubts with regard to the question whether the observed data really is representative, we circumvent any possible bias by excluding these times.

In what follows, we outline six different alternative dividend series which are adjusted for different forms of dividend policies. These alternatives, subsequently referenced as hypothetical dividend series, are then utilized in the tests for bubbles as fundamental, 
translating to dividend policy-adjusted tests thereof.

The first hypothetical dividend time series (called HDREIT) assumes that all firms behave like real estate investment trusts (REITs) and pay $90 \%$ of their income as dividends. While this is a legal requirement for the very special equity market segment REITs in the U.S., the time series is thought to simulate a behavior of firms where almost all cash flows are returned to investors as dividends. Therefore, examining this variable assumes that there is no applied dividend policy other than paying out the majority of earnings.

The second hypothetical dividend time series (referred to as HDWW1) is constructed by calculating the average payout ratio with data from the time before and after the start of WW1. This time series therefore should control for parameter instabilities in the relationship between dividends and corporate earnings that are a result of this war. Moreover, given that WW1 effectively put an end to the classical gold standard, this hypothetical dividend time series should also help to cope with possible data problems that may have resulted from the switch to fiat money after WW1. This might be of some relevance given that inflation, and therefore possibly also the monetary system, seems to matter examining the dividend policy of firms (see, for example, Basse \& Reddemann, 2011, Baker \& Jabbouri, 2017).

The third hypothetical dividend time series (denoted HDWW2) is calculated on the basis of average payout ratios for the time before and after the start of WW2. Chen, Da \& Priestley (2012) have reported empirical evidence that WW2 has affected the dividend policy of U.S. firms. Therefore, we try to control for these effects of WW2 on the relationship between dividends and the profits of the U.S. corporate sector. However, it might be interesting at this point that we have estimated a very simple regression model explaining the first difference of the dividend time series with the first difference of the corporate earnings time series and an constant. Then we perform the test for structural changes with unknown break dates suggested by Bai \& Perron (1998). This test has not been able to detect structural change in the 1940s but in the mid 1990s 4

\footnotetext{
${ }^{4}$ For the sake of the focus of this research, detailed results and empirical evidence on this test is not reported but available upon request.
} 
The fourth hypothetical dividend time series (referenced as $H D B W$ ) is based on the idea that major economic booms and busts or stock market crashes in general can affect the dividend policy of firms in a way that might lead to an atypical behavior of the payout ratio. Hence, we exclude specific years of market turmoil. This idea is based on a paper by Baker \& Wurgler (2004). More specifically, we use the average payout ratio before WW1 to calculate hypothetical dividends from reported earnings prior to the year 1914. When determining the average payout after the start of WW1, we exclude data points that correspond with the stock market crash in 1929 (the years 1930 to 1933), the turbulences in 1987 (the years 1988 and 1989), the dot.com-bubble and its bursting (the years 1996 to 2003), and the subprime debacle (the years 2009 to 2011).

The fifth hypothetical dividend time series (labeled HDNIX03) controls for policy changes and is constructed by firstly splitting the data in two subsets similar to HDWW2. For these subsets, the average payout ratio before the start of WW2 and after are calculated. Most importantly, we control for Nixon's attempt to limit dividend increases in the early 1970s and the changes to the taxation of dividend payouts in 2003 by excluding the data for the years 1972 to 1974 and 2003 to 2014 to calculate the average payout ratio in the second subset after start of WW2.

The sixth hypothetical dividend time series (denoted HDMID) is simply calculated using 5-year non-overlapping averages of the dividend payout ratio in combination with the variable current corporate earnings. This way, we construct a dividend time series which is - to some extent - robust against dividend smoothing activities of firms but is still very similar to the observed dividend payouts. Before we move on to a more detailed analysis, we first examine the relevant time series (see Figures 1 to 4 ).

- insert Figure 1 here -
- insert Figure 2 here -
- insert Figure 3 here -
- insert Figure 4 here - 
First and foremost, it has to be stressed that the dividend payout ratio in the U.S. has declined steadily over time. In fact, Goetzmann, Ibbotson \& Peng (2001) noted that compared to the 20th century the dividend policy of U.S. firms was quite different in the 19th century where a large share of profits were paid out. The practice of retaining earnings was not that common and corporations back then seem to have paid high dividends in order to avoid capital gains. This phenomenon is visualized in Figure 1. The effects of dividend smoothing become very visible during the Financial Crisis in 2008, in which the dividend payout ratio spikes. This sudden increase is due to the fact that the earnings per share is dropping significantly while dividend payouts remain largely unchanged.

Moreover, Figure 2 seems to suggest that a focus on averages of the dividend payout ratio when calculating the hypothetical dividend payout time series is justified. Figures 3 and Figure 4 show stock prices (S\&P 500 equity index and its predecessors), historically observed dividend payouts, and the hypothetical dividend time series that have been constructed from the corporate earnings time series.

\section{Bubble Testing}

In the following, we use the real-time monitoring procedure as proposed by Phillips \& Shi (2020). Compared to previous testing approaches, the main advantage of this novel approach is that the empirical size can be controlled ex ante for a defined period of time. In order to introduce this procedure, we adapt the Data Generating Process (DGP) of Phillips \& Shi (2018). In this framework, the DGP for (log-)prices $p_{t}$ reads as

$$
p_{t}=\left\{\begin{array}{lll}
c_{0} T^{-\eta}+p_{t-1}+\varepsilon_{t}, & t<a=\lfloor A \times T\rfloor, & \text { normal times, } \\
\rho p_{t-1}+\varepsilon_{t}, & t \geq a=\lfloor A \times T\rfloor, & \text { bubble, } \\
\gamma p_{t-1}+\varepsilon_{t}, & t \geq b=\lfloor B \times T\rfloor, & \text { burst, } \\
c_{0} T^{-\eta}+p_{t-1}+\varepsilon_{t}, & t \geq c=\lfloor C \times T\rfloor, & \text { normal times. }
\end{array}\right.
$$

The innovation process $\varepsilon_{t}$ is an independent and identically distributed random variable with $E\left(\varepsilon_{t}\right)=0$ and variance $\sigma^{2}$ for $t=1, \ldots, T$. The parameters $A<B<C \in(0,1)$ 
denote the first observation in the corresponding regimes. The process $p_{t}$ is initialized with $p_{0}$ as a martingale process with a negligible trend $c_{0} T^{-\eta}$, where $c_{0}$ is a constant and $\eta>1 / 2$, for $t=1, \ldots, a-1$. Then, the autoregressive parameter $\rho=1+\delta / \lambda_{T}$, with $\delta>0$ and $\lambda_{T}$ as a sequence which increases to $\infty$ with $\lambda_{T}=o(T)$, renders the price process to be mildly explosive for $t=a, a+1, a+2, \ldots, b-1$. Hence, the asymptotic theory by Phillips \& Magdalinos (2007) for autoregressive time series with a root close to unity is applicable. The collapse is modeled by the stationary autoregressive parameter $|\gamma|<1$ for $t=b, b+1, b+2, \ldots, c-1$. Finally, the log price follows a martingale process with a negligible trend until the end of the sample.

In the first stage we test explosiveness in the price process. If we cannot reject the null hypothesis of the unit root against the explosive alternative, further testing in the price-dividend ratio would no longer be necessary. Given that we find evidence for price explosiveness in the first stage, we test explosiveness in the ratio of the price and the fundamental, or its proxy, $d_{t}$, in the second stage. Phillips, Wu \& Yu (2011) have discussed the degree of integration of the price-dividend-ratio in "normal times" and in bubbles situations. They have pointed out that the price-dividend-ratio is a function of the timevarying discount rate, which might be $I(0)$ or $I(1)$. This plays a subordinate role in times of a bubble as the explosive price - which is an submartingale process - renders the price-dividend-ratio explosive. Hence, the degree of integration of the discount factor is always lower. In "normal times" it plays a role as we have an $I(0)$ or $I(1)$ process for the price-dividend-ratio. However, we specify under the null an $I(1)$ process. This approach is unproblematic since we obtain more conservative results for an $I(0)$ process as the critical values are greater than for an $I(1)$ process (see Phillips, Wu \& Yu, 2011).

The specification of the Augmented Dickey Fuller $(A D F)$ test regression (see Dickey \& Fuller, 1979)

$$
\Delta y_{t}=\mu+\theta y_{t-1}+\sum_{j=1}^{p} \phi_{j} \Delta y_{t-j}+u_{t}
$$


allows to test the pair of hypotheses

$$
\begin{aligned}
& H_{0}: \mu=c_{0} T^{-\eta} \text { and } \theta=0, \\
& H_{A}: \mu=0 \text { and } \theta>0
\end{aligned}
$$

in the framework of Phillips \& Shi (2018) with

$$
y_{t}= \begin{cases}p_{t}, & \text { for the price } \\ p_{t} / d_{t}, & \text { for the price-dividend-ratio }\end{cases}
$$

Hence, under the null hypothesis, $y_{t}$ follows a random walk (with drift) and under the alternative, the process becomes explosive (without drift). The error term $u_{t}$ is allowed to be serially correlated such that

$$
u_{t}=\psi(L) \varepsilon_{t}=\sum_{j=0}^{\infty} \varphi_{j} \epsilon_{t-j}
$$

with $\sum_{j=0}^{\infty} j\left|\varphi_{j}\right|<\infty$ and $\epsilon_{t}$ is a martingale difference sequence. Hence, $\epsilon_{t}$ is potentially conditionally heteroskedastic like in the case of $\mathrm{ARCH}$ or $\mathrm{GARCH}$ errors. Under the alternative, stock prices show temporary explosive behavior and deviate explosively from the fundamental.

As start and end points of the bubble process are unknown in our case, we apply the recursive evolving algorithm by Phillips \& Shi (2020). This approach computes the ADF $t$-ratio of the least squares estimate of coefficient $\theta$ (see regression Eq (7)) recursively from a backward expanding sample sequence. We denote $\tau_{1}$ and $\tau_{2}$ as the start and end points of the regression, respectively, where $\tau_{1}=\left[r_{1} T\right]$ and $\tau_{2}=\left[r_{2} T\right]$ with $[x]$ denoting the integer part of $x$. Hence, the ADF $t$-ratio for the sample between $r_{1}$ and $r_{2}$ is labeled as $A D F_{r_{1}}^{r_{2}}$. Following Phillips, Shi \& Yu (2015), the end point is fixed $r_{2}=r^{\dagger}$ and the start point is allowed to vary over a feasible region $\left[0, r^{\dagger}-r_{0}\right]$. Here, $r_{0}$ denotes the minimum required window size to initiate the regression. We follow the rule by Phillips, Shi \& Yu (2015) and set $r_{0}=0.01+1.8 / \sqrt{T}$. The test statistic for this approach is the supremum 
over the sequence of $\mathrm{ADF} t$-ratios

$$
B S A D F_{r^{\dagger}}\left(r_{0}\right)=\sup _{r_{1} \in\left[0, r^{\dagger}-r_{0}\right], r_{2}=r^{\dagger}}\left\{A D F_{r_{1}}^{r_{2}}\right\}
$$

The procedure is called recursive evolving algorithm because the recursive computation evolves as $r^{\dagger}$ is shifted forward until the end of the sample. Hence, we receive a sequence of $B S A D F_{r^{\dagger}}\left(r_{0}\right)$. Suppose the sample contains one explosive regime, start and end point are given by

$$
\begin{aligned}
& \hat{r}_{e}=\inf _{r^{\dagger} \in\left[r_{0}, \mathrm{u}\right]}\left\{r^{\dagger}: B S A D F_{r^{\dagger}}\left(r_{0}\right)>c v_{r^{\dagger}}\left(\beta_{T}\right)\right\}, \quad \text { and } \\
& \hat{r}_{f}=\inf _{r^{\dagger} \in\left[\hat{r}_{e}, 1\right]}\left\{r^{\dagger}: B S A D F_{r^{\dagger}}\left(r_{0}\right)<c v_{r^{\dagger}}\left(\beta_{T}\right)\right\}
\end{aligned}
$$

respectively. The procedure indicates the start of the explosive regime when the test statistic, $B S A D F_{r^{\dagger}}\left(r_{0}\right)$, exceeds the critical value $c v_{r^{\dagger}}\left(\beta_{T}\right)$ and the end of the explosive regime when the test statistic falls below the critical value.

Critical values are calculated by using the composite bootstrap by Phillips \& Shi (2020) which has been designed to cope with the influence of heteroskedasticity by using a wild bootstrap (see Harvey, Leybourne, Sollis \& Taylor, 2016) and in order to deal with the multiplicity issue in recursive testing procedures (see Shi, Hurn \& Phillips, 2016). Phillips \& Shi (2020) and Shi \& Phillips (2020) describe this approach in five steps:

1. Estimate regression model in Eq. (7) under the imposition of $\rho=0$ and obtain the estimated residuals $\hat{u}_{t}$.

2. Generate a bootstrap sample with initial values $y_{i}^{b}=y_{i}$ for $i=1, \ldots, j+1$ as

$$
\Delta y_{t}^{b}=\sum_{j=1}^{p} \hat{\phi}_{j} \Delta y_{t-j}^{b}+\hat{u}_{t}^{b}
$$

where $\hat{\phi}_{i}$ are estimated coefficients from the first step. The residuals are $\hat{u}_{t}^{b}=w_{t} \hat{u}_{l}$ whereas $\hat{u}_{l}$ is randomly drawn with replacement from the estimated residuals $\hat{u}_{t}$ and $w_{t}$ is randomly drawn from a standard normal distribution.

3. Compute the $B S A D F$ test statistic sequence $\left\{B S A D F_{t}^{b}\right\}_{t=\tau_{0}}^{\tau_{0}+\tau_{b}-1}$ and its maximum 
value denoted by

$$
\mathcal{M}_{t}^{b}=\max _{t \in\left[\tau_{0}, \tau_{0}+\tau_{b}-1\right]}\left(B S A D F_{t}^{b}\right)
$$

from the bootstrapped series.

4. Repeat steps $2-3$ for $B_{n}$ times.

5. The $95 \%$ percentiles of the $\left\{\mathcal{M}_{t}^{b}\right\}_{b=1}^{B}$ sequence gives the critical value for this procedure.

The parameter $\tau_{b}$ denotes the number of observations for which the size of the test is controlled. There is a trade-off between the power of the test procedure by Phillips, Shi \& $\mathrm{Yu}(2015)$ using the (wild) bootstrap by Phillips \& Shi (2020) and the choice of $\tau_{b}$ as the period for which the size is controlled becomes longer, power to detect explosive regimes decreases, ceteris paribus. Hence, we report the results for a range of $\tau_{b} \in\{4,5,6,7,8,9\}$. Thus, we control the size for time spans between 4 and 9 years.5

\section{Empirical Results}

\subsection{Testing for Bubbles using hypothetical Dividends}

In order to test against bubble behavior in the S\&P 500, we have first applied the real time monitoring procedure by Phillips \& Shi (2020) to the price series. The results that can be found in Figure 5 indicate that there are explosive phases. Thus, the necessary condition for a bubble is fulfilled and we consider the sufficient condition in the following.

$$
\text { - insert Figure } 5 \text { here - }
$$

Therefore, we present the results of the monitoring procedure by Phillips \& Shi (2020) applied to the price-dividend (monthly and yearly) ratio and the (yearly) ratios between prices and hypothetical dividends for a significance level of $\alpha=0.05$. As mentioned above, potential issues due to heteroskedasticity and to the effect of family-wise size control in

\footnotetext{
${ }^{5}$ The R-code for this procedure has been implemented in the package psymonitor (Caspi, Phillips \& Shi, 2018). We thank the authors for making the code publicly available.
} 
recursive testing algorithms are mitigated by the bootstrap approach by Phillips \& Shi (2020)..$^{6}$ Lags are selected by the Bayesian information criterion (BIC).$^{7}$

- insert Figure 6 here -

Figure 6 shows the bubble test results for the yearly price-dividend ratio. As noted above, the size control parameter varies from four to nine years. The trade-off between longer sized controlled periods and power leads to less years within the bubble period for larger values of $\tau_{b}$. Nonetheless, the bubble testing procedure indicates strong evidence in favor of a financial bubble in the early 2000s - which is often interpreted as the dot.com-bubbleand coincides with the results by Phillips, Shi \& Yu (2015) and Phillips \& Shi (2020). In order to show the robustness of these results around the period of the dot.com-bubble, we also report the results of the test by Phillips \& Shi (2020) applied to monthly data in Figure 7 .

- insert Figure 7 here -

Start and end periods are consistent with the results for yearly data. Hence we proceed with yearly data for the hypothetical dividends. As motivated above, we use yearly data to avoid seasonal patterns and due to limitations of data availability.

However, if we assume that all firms behave like REITs and pay $90 \%$ of its income as a dividend, the results in favor of financial bubble becomes less striking. Figure 8 shows the results of the test by Phillips \& Shi (2020) applied to the ratio of the price and the hypothetical REIT dividend. For $\tau_{b} \in\{5,6,7\}$ we find only one explosive period each. For $\tau_{b} \in\{8,9\}$, the bubble disappears completely.

- insert Figure 8 here -

This result holds also when we control for parameter instability due to WW1 (HDWW1)as presented by Figure 9 and for WW2 (HDWW2) - as presented by Figure 10.

\footnotetext{
${ }^{6}$ The procedures by Phillips, Shi \& Yu (2015) and Phillips \& Shi (2020) are implemented and available within the $\mathrm{R}$ package psymonitor.

${ }^{7}$ Our results remain robust by using the Akaike information criterion (AIC). Results are not reported in order to conserve space and are available on request.
} 
- insert Figure 9 here -

- insert Figure 10 here -

When we control additionally for major economic booms and bursts $(H D B W)$, we receive maximum two explosive period as shown by Figure 11 .

- insert Figure 11 here -

Figure 12 presents the results when we control for WW2, Nixon's attempt to limit dividend increases, and the tax reform of 2003. Also in this case, there is only weak evidence for explosiveness. Again, for $\tau_{b} \in\{8,9\}$, the bubble disappears completely.

- insert Figure 12 here -

If we use the 5 year non-overlapping averages of the dividend payout ratio combined with corporate earnings such that the dividend process is not that strongly affected by the dividend smoothing activities of firms, we receive comparable results as for the pricedividend ratio.

- insert Figure 13 here -

Finally, we form an equally weighted average over the hypothetical dividends (without HDMID) denoted by MidProxies and test against explosiveness here as well. Figure 14 reports the results which are very similar to the hypothetical dividend series - also in this case evidence for a shorter bubble phase is found.

- insert Figure 14 here -

Nonetheless, even if we cannot rule out the bubble completely, the majority of our results indicate much less compelling evidence for bubbles compared to commonly adapted testing approach based on observed dividends. Table 1 and Table 2 summarize the results by presenting the start and end points of the explosive regimes.

- insert Table 1 here -

- insert Table 2 here - 
We have also considered the properties of the differences between actual and hypothetical dividends. First of all, as mentioned above, managers in firms try to avoid situation in which they need to cut sharply or even to omit dividend payments. Assuming that dividends are smoothed, the time series of realized dividend payouts should in total show less momentum than the time series of the hypothetical dividends. In principle, this might not lead to a reduction (or increase) in the degree of integration. Only the dynamics of the explosive behavior might be different for the realized and the hypothetical dividend series. Furthermore, in situation in which the price-dividend ratio fails to provide conclusive evidence about bubbles as the rejection of the null hypothesis of no bubble is due to a miss-specification of the fundamental caused by dividend smoothing, the difference between the actual and the hypothetical dividend which accounts for dividend smoothing should be explosive. Therefore, we have tested against explosiveness in the series constructed as the difference between the actual and hypothetical dividends. The following figures show the results for HDNIX03, HDWW1, HDWW2, and HDBW. The parameter $\tau_{b}$ is set to 7 in all cases. 8

\section{- insert Figure 15 here -}

As expected, the hypothetical dividends are systematically larger than the realized dividends in "regular" times. Further, the gray shaded areas in Figure 15 indicate periods of explosive behavior which coincide with the explosive price phases. Hence, we conclude that accounting for dividend smoothing leads to less persuasive evidence in favor of a bubble in the S\&P during the early 2000s.9

\subsection{Granger Causality between (hypothetical) Dividends and Spot Prices}

According to Eq. (2), today's stock prices should help to forecast future expected dividend payouts, respectively hypothetical dividends - which, in our case, are functions

\footnotetext{
${ }^{8}$ Note that the results do not vary qualitatively with the choice of $\tau_{b}$ in this case. Therefore, we omit additional results here for several specification in order to conserve space. Nonetheless, these results are available on request.

${ }^{9}$ Our approach involves the log-linearization by Campbell \& Shiller (1988). In the presence of large explosive bubbles, Engsted, Pedersen \& Tanggaard (2012) show that the Campbell-Shiller approximation is very accurate. For additional robustness, we test for explosiveness in the difference between log prices and the log (hypothetical) dividend series. The results lead to exactly the same conclusions and are not reported in order to conserve space, but are available on request. We thank reviewer 1 for this comment.
} 
of corporate earnings. Therefore, there should be Granger causality running from stock prices today to future dividends/hypothetical dividends. However, there are dividend and earnings surprises which are-by definition-not expected by investors. Therefore, past values of dividends and hypothetical dividends, which are calculated from corporate earnings, could also Granger cause stock prices. In fact, finding empirical evidence pointing in this direction would indicate that a time series could be a "good" or suitable fundamental. We test for Granger causality between 1945 and 1998 among stock prices and realized as well as hypothetical dividend payouts using the test by Toda \& Yamamoto (1995). On one hand, there is no evidence at the $5 \%$ level-which is of central importance in this paper - for Granger causality between stock prices and realized dividend payouts. At the $10 \%$ level, there is empirical evidence for unidirectional Granger causality running from stock prices to dividends. On the other hand, there is clear evidence for unidirectional Granger causality running from the hypothetical dividend time series to stock prices. This empirical finding implies that these variables should be a more useful fundamental than the realized dividend payouts. 10

\subsection{An alternative Approach: Using Market Expectation to test Bubbles}

Furthermore, the price-dividend ratio might fail to provide conclusive evidence about bubbles as the rejection of the null hypothesis of no bubble might be due to the existence of bubbles or a miss-specified fundamental or both. Pavlidis, Paya \& Peel (2017) provide the most recent approach which does not require the specification of the fundamental. The authors argue that the futures price is a biased forecast of the spot price in the future if a bubble exists and hence, the spread between future spot and forwards would behave explosively in this case. The authors apply the test by Phillips, Shi \& Yu (2015) to the differences between the future spot and futures prices and report empirical evidence in favor of a financial bubble in the S\&P 500 as Phillips, Shi \& Yu $(2015)$ do. However, the results of Pavlidis, Paya \& Peel (2017) are less compelling compared to Phillips, Shi \& Yu $(2015)$ - in the sense that the explosive periods in the futures and future spot price spread

\footnotetext{
${ }^{10}$ In order to conserve space, these results are not reported in detail but are available on request. We thank an anonymous reviewer for these detailed comments that resulted in those tests.
} 
are shorter compared to the explosive periods of the price-dividend ratio-which indicates that the specification of the fundamental process plays an important role. We apply the same methodology as in Pavlidis, Paya \& Peel (2017) using spot and futures prices ${ }^{11}$ between $07 / 1983$ and 12/2014 with one exception - we use the bootstrap procedure by Phillips \& Shi (2020) to obtain critical values for the test by Phillips, Shi \& Yu (2015). The results are reported in Table 3.

- insert Table 3 here -

With this modification, a very short explosive period could only be found for the spread between the spot and the futures price with nine month maturity in the course of the Dot.com bubble. Hence, the bubble testing results using the hypothetical dividends as the proxy for the fundamental match the results of the procedure by Pavlidis, Paya \& Peel (2017) better compared the approach where actual dividends are used. Together with the empirical result that we obtain unidirectional Granger causality between prices and hypothetical dividends, but not between spot prices and actual dividends, this can be interpreted as evidence that hypothetical dividends contain more information about future spot prices than actual dividends do.

\section{Conclusions}

The main goal of this paper is to link empirical evidence reported in literature of testing for bubbles more strongly to corporate finance literature. In order to do so, we focus on dividend policy issues. Given that there is some empirical evidence for dividend smoothing in the U.S., there could be doubts whether observed dividend payments really are a useful fundamental factor while using recursive right-tailed unit root tests to identify bubbles.

Therefore, we have constructed hypothetical dividend payouts which are based on reported corporate earnings. The empirical evidence presented above does suggest that

\footnotetext{
${ }^{11}$ We utilize weekly prices of S\&P 500 futures from the Chicago Mercantile Exchange (CME) that expire on quarterly basis. We construct continuous three-, six-, nine-, and twelve-month futures prices by spline-interpolation, making use of the next four available quarterly futures as sampling points. CME's rollover specifications for the definition of the lead month contract are taken into consideration. All data is available upon request.
} 
dividend policy could indeed matter when testing for speculative bubbles. In fact, the dot.com-bubble, that is commonly seen as the prime example for a stock price bubble not only in the NASDAQ but also in other broader U.S. equity indices, can be diagnosed with the observed dividend time series examining the $\mathrm{S} \& \mathrm{P} 500$. This is not necessarily the case with our hypothetical dividend time series if we adjust for dividend policy. Given that both - the efficient market hypothesis, which predicts that there should be no speculative bubbles in financial market prices, and the dividend irrelevancy theorem-rely on the assumption of perfect markets, it is interesting to note that the empirical evidence is less striking for financial bubbles by controlling for dividend policy. With the observation that firms in the U.S. take measures to smooth dividends, which - under the assumption of perfect markets - should be regarded as an inefficient waste of time and resources, the utilization of observed dividends for bubble testing might be misleading. We demonstrate that by adjusting these observed dividend series with dividend policy, adherents of the efficient market theory might overcome the problem that the now commonly employed tests usually indicate the existence of the dot.com-bubble in the S\&P 500.

With regard to asset price bubbles, we seek to ascertain whether attention to the existence dividend smoothing of firms might save the efficient market theory. This central question is to be answered with a cautious "yes," under the consideration of additional factors. Taking into account that firms smooth their dividend payments to a certain degree clearly yields less substantial empirical evidence for the existence of speculative price bubbles in the S\&P 500. The assumption that asset price bubbles should not exist is one of the fundamentals of the efficient market hypothesis. Therefore, the evidence presented here is of high relevance to the practical implications of the efficient market hypothesis. In addition, considering that many firms seem to follow a specific dividend policy could indeed rescue the efficient market theory - at least in parts - in terms of testing for the existence of speculative bubbles by using dividends as fundamental factor. Some problems remain. Most importantly, our hypothetical dividend payouts are constructed from corporate earnings - and firms might also use earnings smoothing (see, for example, Baker \& Weigand, 2015, Gao \& Zhang, 2015). At this point, it has to be noted that 
there are close linkages to the accounting literature, for example Khalil \& Simon (2014) and Di \& Marciukaityte (2015). In addition, Gao \& Zhang (2015) already discuss the effects of earnings smoothing via accounting discretion from the perspective of corporate finance theory. Thus, reported earnings are not necessarily a perfect proxy for economic fundamentals.

In this paper, we develop several techniques to handling the distorting effects of the dividend policy of firms in the context of valuation models. Thus, the alternative dividend payout time series constructed in this paper should provide better information about the payouts expected by market participants. As a matter of fact, we evidently find less compelling evidence for the existence of a speculative bubble in the S\&P 500 when the hypothetical dividend payments are used as fundamental factors. In any case, our results which provide a strong link between the financial bubble and dividend policy literature could indeed proof to be a very promising research direction for future empirical research. 


\section{References}

Acharya, V. V., \& Lambrecht, B. M. (2015). A Theory of Income Smoothing When Insiders Know More Than Outsiders. Review of Financial Studies, 28, 2534-2574. doi:10.1093/rfs/hhv026.

Agrawal, A., \& Jayaraman, N. (1994). The dividend policies of all-equity firms: A direct test of the free cash flow theory. Managerial and Decision Economics, 15, 139-148. URL: http://doi.wiley.com/10.1002/mde.4090150206. doi:10.1002/mde. 4090150206.

Alessandri, P. (2006). Bubbles and fads in the stock market: Another look at the experience of the US. International Journal of Finance \& Economics, 11, 195-203. URL: http://doi.wiley.com/10.1002/ijfe.292, doi:10.1002/ijfe.292.

Allen, F., Bernardo, A. E., \& Welch, I. (2000). A theory of dividends based on tax clienteles. The Journal of Finance, 55, 2499-2536. URL: http://doi.wiley.com/10. 1111/0022-1082.00298, doi:10.1111/0022-1082.00298

Alli, K. L., Khan, A. Q., \& Ramirez, G. G. (1993). Determinants of corporate dividend policy: A factorial analysis. The Financial Review, 28, 523547. URL: http://doi.wiley.com/10.1111/j.1540-6288.1993.tb01361.x. doi:10. $1111 / \mathrm{j} .1540-6288.1993 . \mathrm{tb01361.x}$

Bai, J., \& Perron, P. (1998). Estimating and testing linear models with multiple structural changes. Econometrica, 66, 47-78. URL: http://www.jstor.org/stable/2998540

Baker, H. K., Farrelly, G. E., \& Edelman, R. B. (1985). A survey of management views on dividend policy. Financial Management, 14, 78-84. URL: http://doi.wiley.com/ 10.2307/3665062, doi $10.2307 / 3665062$.

Baker, H. K., \& Jabbouri, I. (2017). How Moroccan institutional investors view dividend policy. Managerial Finance, 43, 1332-1347.

Baker, H. K., Veit, E. T., \& Powell, G. E. (2001). Factors influencing dividend policy decisions of NASDAQ firms. The Financial Review, 36, 19 38. URL: http://doi.wiley.com/10.1111/j.1540-6288.2001.tb00018.x. doi:10. $1111 / \mathrm{j} .1540-6288.2001 . \mathrm{tb00018.x}$.

Baker, H. K., \& Weigand, R. (2015). Corporate dividend policy revisited. Managerial Finance, 41, 126-144. URL: http://www.emeraldinsight.com/doi/10.1108/ MF-03-2014-0077. doi:10.1108/MF-03-2014-0077.

Baker, M., \& Wurgler, J. (2004). Appearing and disappearing dividends: The link to catering incentives. Journal of Financial Economics, 73, 271288. URL: https://linkinghub.elsevier.com/retrieve/pii/S0304405X04000078. doi:10.1016/j.jfineco.2003.08.001.

Basse, T., \& Reddemann, S. (2011). Inflation and the dividend policy of US firms. Managerial Finance, 37, 34-46. URL: https://www.emerald.com/insight/content/ doi/10.1108/03074351111092139/full/html, doi:10.1108/03074351111092139. 
Beer, F. M. (1993). Dividend signalling equilibria: Quantitative evidence from the Brussels stock exchange. The Financial Review, 28, 139-157. URL: http://doi.wiley.com/ 10.1111/j.1540-6288.1993.tb01342.x doi:10.1111/j.1540-6288.1993.tb01342. $\mathrm{X}$.

Black, F. (1976). The dividend puzzle. The Journal of Portfolio Management, 2, 5-8. URL: http://jpm.pm-research.com/lookup/doi/10.3905/jpm.1976.408558. doi:10.3905/jpm.1976.408558

Blanchard, O., \& Watson, M. (1982). Bubbles, Rational Expectations and Financial Markets. Technical Report National Bureau of Economic Research Cambridge, MA. URL: http://www .nber.org/papers/w0945.pdf, doi:10.3386/w0945.

Bonaimé, A. A., Hankins, K. W., \& Harford, J. (2014). Financial flexibility, risk management, and payout choice. Review of Financial Studies, 27, 1074-1101. URL: https://academic .oup.com/rfs/article-lookup/doi/10.1093/rfs/hht045. doi:10.1093/rfs/hht045.

Campbell, J. Y., \& Shiller, R. J. (1988). The dividend-price ratio and expectations of future dividends and discount factors. The Review of Financial Studies, 1, 195-228.

Caspi, I., Phillips, P. C. B., \& Shi, S. (2018). psymonitor: Real Time Monitoring of Asset Markets. URL: https://itamarcaspi.github.io/psymonitor/ r package version 0.0 .1 .

Chen, L., Da, Z., \& Priestley, R. (2012). Dividend smoothing and predictability. Management Science, 58, 1834-1853. URL: http://pubsonline.informs.org/doi/abs/ $10.1287 / \mathrm{mnsc} .1120 .1528$, doi:10.1287/mnsc.1120.1528.

Dewenter, K. L., \& Warther, V. A. (1998). Dividends, asymmetric information, and agency conflicts: Evidence from a comparison of the dividend policies of Japanese and U.S. firms. The Journal of Finance, 53, 879-904. URL: http://doi.wiley.com/10. 1111/0022-1082.00038, doi:10.1111/0022-1082.00038

Di, H., \& Marciukaityte, D. (2015). Earnings smoothing around open-market share repurchases. Review of Accounting and Finance, 14, 64-80. doi:10.1108/ RAF-10-2012-0111

Diba, B. T., \& Grossman, H. I. (1988). Explosive rational bubbles in stock prices? American Economic Review, 78, 520-530. URL: https://www.jstor.org/stable/ 1809149 .

Dickey, D. A., \& Fuller, W. A. (1979). Distribution of the estimators for autoregressive time series with a unit root. Journal of the American Statistical Association, 74, 427-431. URL: http://www.tandfonline.com/doi/abs/10.1080/ 01621459.1979 .10482531 , doi:10.1080/01621459.1979.10482531.

Engsted, T., Hviid, S. J., \& Pedersen, T. Q. (2016). Explosive bubbles in house prices? evidence from the OECD countries. Journal of International Financial Markets, Institutions and Money, 40, 14-25. 
Engsted, T., Pedersen, T. Q., \& Tanggaard, C. (2012). The log-linear return approximation, bubbles, and predictability. Journal of Financial and Quantitative Analysis, (pp. 643-665).

Evans, G. (1991). Pitfalls in testing for explosive bubbles in asset prices. American Economic Review, 81, 922-930.

Figuerola-Ferretti, I., McCrorie, J. R., \& Paraskevopoulos, I. (2019). Mild explosivity in recent crude oil prices. Energy Economics, forthcoming. URL: https://linkinghub. elsevier.com/retrieve/pii/S0140988319301471. doi:10.1016/j.eneco.2019.05. 002 .

Fliers, P. T. (2019). What is the relation between financial flexibility and dividend smoothing? Journal of International Money and Finance, 92, 98-111. doi:10.1016/ j.jimonfin.2018.12.009.

Floyd, E., Li, N., \& Skinner, D. J. (2015). Payout policy through the financial crisis: The growth of repurchases and the resilience of dividends. Journal of Financial Economics, 118, 299-316. URL: https://linkinghub.elsevier.com/retrieve/pii/ S0304405X15001415, doi:10.1016/j.jfineco.2015.08.002.

Frankfurter, G. M., \& Lane, W. R. (1992). The rationality of dividends. International Review of Financial Analysis, 1, 115-129. URL: http://www. sciencedirect.com/science/article/pii/S1057521915300107. doi:https://doi. org/10.1016/S1057-5219(15)30010-7.

Gao, L., \& Zhang, J. H. (2015). Firms' earnings smoothing, corporate social responsibility, and valuation. Journal of Corporate Finance, 32, 108-127. URL: http: //www.sciencedirect.com/science/article/pii/S0929119915000449 doi:https: //doi.org/10.1016/j.jcorpfin.2015.03.004.

Ghosh, C., \& Woolridge, J. R. (1989). Stock-market reaction to growth-induced dividend cuts: Are investors myopic? Managerial and Decision Economics, 10, 25-35. URL: http://doi.wiley.com/10.1002/mde.4090100104. doi:10.1002/mde.4090100104.

Goddard, J., McMillan, D. G., \& Wilson, J. O. (2006). Dividend smoothing vs dividend signalling: Evidence from UK firms. Managerial Finance, 32, 493504. URL: https://www.emeraldinsight.com/doi/10.1108/03074350610666229. doi:10.1108/03074350610666229.

Goetzmann, W. N., Ibbotson, R. G., \& Peng, L. (2001). A new historical database for the NYSE 1815 to 1925: Performance and predictability. Journal of Financial Markets, 4, 1-32. URL: http://www.sciencedirect.com/science/article/pii/ S1386418100000136, doi:https://doi.org/10.1016/S1386-4181(00)00013-6.

Gronwald, M. (2016). Explosive oil prices. Energy Economics, 60, 15. URL: https://linkinghub.elsevier.com/retrieve/pii/S014098831630250X. doi:10.1016/j.eneco.2016.09.012.

Guan, J. X., Li, O. Z., \& Ma, J. (2018). Managerial ability and the shareholder tax sensitivity of dividends. Journal of Financial and Quantitative Analysis, 53, 335-364. URL: https://www.cambridge.org/core/product/identifier/ S0022109017001004/type/journal_article. doi:10.1017/S0022109017001004. 
Handley, J. (2008). Dividend policy: Reconciling DD with MM. Journal of Financial Economics, 87, 528-531. URL: https://linkinghub.elsevier.com/retrieve/pii/ S0304405X0700164X doi:10.1016/j.jfineco.2007.02.002.

Harvey, D. I., Leybourne, S. J., Sollis, R., \& Taylor, A. R. (2016). Tests for explosive financial bubbles in the presence of non-stationary volatility. Journal of Empirical Finance, 38, 548-574. URL: https://linkinghub.elsevier.com/retrieve/pii/ S0927539815000961. doi:10.1016/j.jempfin.2015.09.002.

Hoang, E. C., \& Hoxha, I. (2016). Corporate payout smoothing: A variance decomposition approach. Journal of Empirical Finance, 35, 1-13. doi:10.1016/j·jempfin.2015.10. 011.

Homm, U., \& Breitung, J. (2012). Testing for speculative bubbles in stock markets: A comparison of alternative methods. Journal of Financial Econometrics, 10, 198-231. URL: https://academic.oup.com/jfec/article-lookup/doi/ 10.1093/jjfinec/nbr009, doi:10.1093/jjfinec/nbr009.

Julio, B., \& Ikenberry, D. L. (2004). Reappearing dividends. Journal of Applied Corporate Finance, 16, 89-100. URL: http://doi.wiley.com/10.1111/j.1745-6622. 2004.00010.x doi:10.1111/j.1745-6622.2004.00010.x

Khalil, M., \& Simon, J. (2014). Efficient contracting, earnings smoothing and managerial accounting discretion. Journal of Applied Accounting Research, 15, 100-123. doi:10. 1108/JAAR-06-2012-0050.

Kivedal, B. K. (2013). Testing for rational bubbles in the US housing market. Journal of Macroeconomics, 38, 369-381.

Kruse, R., \& Wegener, C. (2019). Time-varying persistence in real oil prices and its determinant. Energy Economics, forthcoming. URL: https://linkinghub.elsevier. com/retrieve/pii/S0140988319300805, doi:10.1016/j.eneco.2019.02.020.

Lambrecht, B. M., \& Myers, S. C. (2012). A Lintner Model of Payout and Managerial Rents. The Journal of Finance, 67, 1761-1810. doi:10.1111/j.1540-6261.2012. 01772.x.

Leary, M. T., \& Michaely, R. (2011). Determinants of dividend smoothing: Empirical evidence. Review of Financial Studies, 24, 3197-3249. URL: https://academic.oup. com/rfs/article-lookup/doi/10.1093/rfs/hhr072. doi:10.1093/rfs/hhr072.

Lie, E. (2005). Operating performance following dividend decreases and omissions. Journal of Corporate Finance, 12, 27-53. URL: https://linkinghub.elsevier.com/ retrieve/pii/S0929119904000483, doi:10.1016/j.jcorpfin.2004.04.004.

Lintner, J. (1956). Distribution of incomes of corporations among dividends, retained earnings, and taxes. American Economic Review, 46, 97-113.

Mann, S. V. (1989). The dividend puzzle: A progress report. Quarterly Journal of Business and Economics, 28, 3-35. doi:0747-5535/89/1400-0003.

Marsh, T. A., \& Merton, R. C. (1986). Dividend variability and variance bounds tests for the rationality of stock market prices. American Economic Review, 76, 483-498. 
Michaely, R., Thaler, R. H., \& Womack, K. L. (1995). Price reactions to dividend initiations and omissions: Overreaction or drift? The Journal of Finance, 50, 573-608. URL: http://doi.wiley.com/10.1111/j.1540-6261.1995.tb04796.x. doi:10.1111/j.1540-6261.1995.tb04796.x.

Miller, M. H., \& Modigliani, F. (1961). Dividend policy, growth, and the valuation of shares. The Journal of Business, 34, 411-433.

Pavlidis, E. G., Paya, I., \& Peel, D. A. (2017). Testing for speculative bubbles using spot and forward prices. International Economic Review, 58, 1191-1226. URL: http: //doi.wiley.com/10.1111/iere.12249. doi:10.1111/iere.12249.

Pavlidis, E. G., Paya, I., \& Peel, D. A. (2018). Using market expectations to test for speculative bubbles in the crude oil market. Journal of Money, Credit and Banking, 50, 833-856. URL:http://doi.wiley.com/10.1111/jmcb.12525. doi:10.1111/jmcb. 12525 .

Phillips, P. C., \& Magdalinos, T. (2007). Limit theory for moderate deviations from a unit root. Journal of Econometrics, 136, 115-130. URL: https://linkinghub.elsevier. com/retrieve/pii/S0304407605002034 doi:10.1016/j·jeconom.2005.08.002.

Phillips, P. C., \& Shi, S. (2020). Real time monitoring of asset markets: Bubbles and crises. In Handbook of Statistics (pp. 61-80). URL: https://linkinghub.elsevier. com/retrieve/pii/S0169716118301068. doi:10.1016/bs.host.2018.12.002.

Phillips, P. C., \& Shi, S.-P. (2018). Financial bubble implosion and reverse regression. Econometric Theory, 34, 705-753. URL: https://www.cambridge. org/core/product/identifier/S0266466617000202/type/journal_article. doi:10.1017/S0266466617000202.

Phillips, P. C. B., Shi, S., \& Yu, J. (2015). Testing for multiple bubbles: Historical episodes of exuberance and collapse in the S\&P 500. International Economic Review, 56, 10431078. URL: http://doi.wiley.com/10.1111/iere.12132, doi:10.1111/iere.12132,

Phillips, P. C. B., Wu, Y., \& Yu, J. (2011). Explsoive behavior in the 1990s NASDAQ: When did exuberance escalate asset values? International Economic Review, 52, 201-226. URL: http://doi.wiley.com/10.1111/j.1468-2354.2010.00625.x. doi:10.1111/j.1468-2354.2010.00625.x.

Phillips, P. C. B., \& Yu, J. (2011). Dating the timeline of financial bubbles during the subprime crisis. Quantitative Economics, 2, 455-491. URL: http://doi.wiley.com/ 10.3982/QE82. doi:10.3982/QE82.

Reddemann, S., Basse, T., \& von der Schulenburg, J.-M. G. (2010). On the impact of the financial crisis on the dividend policy of the European insurance industry. The Geneva Papers on Risk and Insurance - Issues and Practice, 35, 53-62. URL: http: //link.springer.com/10.1057/gpp.2009.37, doi:10.1057/gpp.2009.37.

Shi, S., \& Phillips, P. C. (2020). Diagnosing housing fever with an econometric thermometer, . 
Shi, S.-P., Hurn, S., \& Phillips, P. C. B. (2016). Causal change detection in possibly integrated systems: Revisiting the money-income relationship. URL: http://www. ssrn.com/abstract=2881983, doi:10.2139/ssrn.2881983.

Shiller, R. J. (1986). The Marsh-Merton model of managers' smoothing of dividends. American Economic Review, 76, 499-503.

Shiller, R. J. (2014). Speculative asset prices. American Economic Review, 104, 14861517. URL: http://pubs.aeaweb.org/doi/10.1257/aer.104.6.1486. doi:10.1257/ aer.104.6.1486

Short, H., Zhang, H., \& Keasey, K. (2002). The link between dividend policy and institutional ownership. Journal of Corporate Finance, 8, 105-122. URL: http: //www.sciencedirect.com/science/article/pii/S092911990100030X. doi:https: //doi.org/10.1016/S0929-1199(01)00030-X.

Toda, H. Y., \& Yamamoto, T. (1995). Statistical inference in vector autoregressions with possibly integrated processes. Journal of Econometrics, 66, 225-250.

Wald, J. (1999). Capital structure with dividend restrictions. Journal of Corporate Finance, 5, 193-208. URL:/http://www.sciencedirect.com/science/article/pii/ S0929119998000200, doi:https://doi.org/10.1016/S0929-1199(98)00020-0.

West, K. D. (1988). Bubbles, fads and stock price volatility tests: A partial evaluation. The Journal of Finance, 43, 639-656. URL: http://doi.wiley.com/10.1111/ j.1540-6261.1988.tb04596.x. doi:10.1111/j.1540-6261.1988.tb04596.x.

Wilson, J. W., \& Jones, C. P. (2002). An analysis of the S\&P 500 index and Cowles's extensions: Price indexes and stock returns, 1870-1999. The Journal of Business, 75, 505-533. URL: http://www.jstor.org/stable/10.1086/339903. 


\section{Appendix}

\begin{tabular}{|c|c|c|c|c|c|c|}
\hline & $\tau_{b}=4$ & $\tau_{b}=5$ & $\tau_{b}=6$ & $\tau_{b}=7$ & $\tau_{b}=8$ & $\tau_{b}=9$ \\
\hline \multicolumn{7}{|c|}{ Monthly price-dividend ratio $(01 / 1973$ to $12 / 2014)$} \\
\hline$\hat{r}_{e, 1}$ & $11 / 1996$ & $11 / 1996$ & $11 / 1996$ & 06/1997 & 06/1997 & 06/1997 \\
\hline$\hat{r}_{f, 1}$ & $12 / 1996$ & $12 / 1996$ & $12 / 1996$ & $07 / 1997$ & $08 / 1997$ & 08/1997 \\
\hline$\hat{r}_{e, 2}$ & $01 / 1997$ & 05/1997 & $05 / 1997$ & 09/1997 & 09/1997 & 09/1997 \\
\hline$\hat{r}_{f, 2}$ & $02 / 1997$ & $08 / 1998$ & $08 / 1998$ & $10 / 1997$ & $10 / 1997$ & $10 / 1997$ \\
\hline$\hat{r}_{e, 3}$ & $05 / 1997$ & $11 / 1998$ & $11 / 1998$ & $11 / 1997$ & $11 / 1997$ & $11 / 1997$ \\
\hline$\hat{r}_{f, 3}$ & 08/1998 & $11 / 2000$ & $11 / 2000$ & 08/1998 & 08/1998 & 08/1998 \\
\hline$\hat{r}_{e, 4}$ & $10 / 1998$ & $10 / 2008$ & $10 / 2008$ & $11 / 1998$ & $11 / 1998$ & $11 / 1998$ \\
\hline$\hat{r}_{f, 4}$ & $11 / 2000$ & $12 / 2008$ & $12 / 2008$ & 09/1999 & 09/1999 & 09/1999 \\
\hline$\hat{r}_{e, 5}$ & $10 / 2008$ & $01 / 2009$ & $01 / 2009$ & 10/1999 & 10/1999 & 10/1999 \\
\hline$\hat{r}_{f, 5}$ & $03 / 2009$ & $03 / 2009$ & $03 / 2009$ & $08 / 2000$ & $09 / 2000$ & $05 / 2000$ \\
\hline$\hat{r}_{e, 6}$ & & & & $10 / 2008$ & $11 / 2008$ & $06 / 2000$ \\
\hline$\hat{r}_{f, 6}$ & & & & $12 / 2008$ & $12 / 2008$ & $07 / 2000$ \\
\hline$\hat{r}_{e, 7}$ & & & & $02 / 2009$ & $02 / 2009$ & $08 / 2000$ \\
\hline$\hat{r}_{f, 7}$ & & & & $03 / 2009$ & $03 / 2009$ & $09 / 2000$ \\
\hline$\hat{r}_{e, 8}$ & & & & & & $11 / 2008$ \\
\hline$\hat{r}_{f, 8}$ & & & & & & $12 / 2008$ \\
\hline$\hat{r}_{e, 9}$ & & & & & & $02 / 2009$ \\
\hline$\hat{r}_{f, 9}$ & & & & & & $03 / 2009$ \\
\hline \multicolumn{7}{|c|}{ Yearly price-dividend ratio (1871 to 2014 ) } \\
\hline$\hat{r}_{e, 1}$ & 1918 & 1918 & 1998 & 1998 & 1998 & 1998 \\
\hline$\hat{r}_{f, 1}$ & 1919 & 1919 & 2002 & 2002 & 2002 & 2002 \\
\hline$\hat{r}_{e, 2}$ & 1997 & 1997 & 2004 & 2004 & & 2004 \\
\hline$\hat{r}_{f, 2}$ & 2005 & 2005 & 2005 & 2005 & & 2005 \\
\hline
\end{tabular}

Table 1: The table presents the start $\left(\hat{r}_{e}\right)$ and end dates $\left(\hat{r}_{f}\right)$ of the explosiveness monitoring procedure by Phillips \& Shi (2020) with a significance level of $\alpha=0.05$ applied to monthly (01/1973 to 12/2014) and yearly (1871 to 2014) price-dividend ratios for the S\&P 500. The size controlling parameter $\tau_{b}$ varies from four to nine. 


\begin{tabular}{|c|c|c|c|c|c|c|}
\hline & $\tau_{b}=4$ & $\tau_{b}=5$ & $\tau_{b}=6$ & $\tau_{b}=7$ & $\tau_{b}=8$ & $\tau_{b}=9$ \\
\hline \multicolumn{7}{|c|}{ Yearly price-HDREIT ratio (1871 to 2014 ) } \\
\hline$\hat{r}_{e, 1}$ & 2001 & 2001 & 2001 & 2001 & & \\
\hline$\hat{r}_{f, 1}$ & 2002 & 2002 & 2002 & 2002 & & \\
\hline$\hat{r}_{e, 2}$ & 2008 & & & & & \\
\hline$\hat{r}_{f, 2}$ & 2009 & & & & & \\
\hline \multicolumn{7}{|c|}{ Yearly price- $H D W W 1$ ratio (1871 to 2014 ) } \\
\hline$\hat{r}_{e, 1}$ & 2001 & 2001 & 2001 & 2001 & & \\
\hline$\hat{r}_{f, 1}$ & 2002 & 2002 & 2002 & 2002 & & \\
\hline$\hat{r}_{e, 2}$ & 2008 & & & & & \\
\hline$\hat{r}_{f, 2}$ & 2009 & & & & & \\
\hline \multicolumn{7}{|c|}{ Yearly price- $H D W W 2$ ratio (1871 to 2014 ) } \\
\hline$\hat{r}_{e, 1}$ & 2001 & 2001 & 2001 & 2001 & & \\
\hline$\hat{r}_{f, 1}$ & 2003 & 2002 & 2002 & 2002 & & \\
\hline$\hat{r}_{e, 2}$ & 2008 & 2008 & 2008 & & & \\
\hline$\hat{r}_{f, 2}$ & 2009 & 2009 & 2009 & & & \\
\hline \multicolumn{7}{|c|}{ Yearly price- $H D B W$ ratio (1871 to 2014 ) } \\
\hline$\hat{r}_{e, 1}$ & 2001 & 2001 & 2001 & 2001 & & \\
\hline$\hat{r}_{f, 1}$ & 2002 & 2002 & 2002 & 2002 & & \\
\hline$\hat{r}_{e, 2}$ & 2008 & & & & & \\
\hline$\hat{r}_{f, 2}$ & 2009 & & & & & \\
\hline \multicolumn{7}{|c|}{ Yearly price-HDNIX03 ratio (1871 to 2014) } \\
\hline$\hat{r}_{e, 1}$ & 2001 & 2001 & 2001 & 2001 & & \\
\hline$\hat{r}_{f, 1}$ & 2003 & 2002 & 2002 & 2002 & & \\
\hline$\hat{r}_{e, 2}$ & 2008 & 2008 & 2008 & & & \\
\hline$\hat{r}_{f, 2}$ & 2009 & 2009 & 2009 & & & \\
\hline \multicolumn{7}{|c|}{ Yearly price- $H D M I D$ ratio (1871 to 2014 ) } \\
\hline$\hat{r}_{e, 1}$ & 1996 & 1996 & 1997 & 1998 & 1998 & 1998 \\
\hline$\hat{r}_{f, 1}$ & 2004 & 2004 & 2003 & 2003 & 1999 & 1999 \\
\hline$\hat{r}_{e, 2}$ & 2008 & 2008 & & & 2000 & 2000 \\
\hline$\hat{r}_{f, 2}$ & 2009 & 2009 & & & 2003 & 2003 \\
\hline
\end{tabular}

Table 2: The table presents the start $\left(\hat{r}_{e}\right)$ and end dates $\left(\hat{r}_{f}\right)$ of the explosiveness monitoring procedure by Phillips \& Shi (2020) with a significance level of $\alpha=0.05$ applied to ratios of prices and hypothetical dividend series for the S\&P 500. The size controlling parameter $\tau_{b}$ varies from four to nine. 


\begin{tabular}{c|cccccc}
\hline & $\tau_{b}=4$ & $\tau_{b}=5$ & $\tau_{b}=6$ & $\tau_{b}=7$ & $\tau_{b}=8$ & $\tau_{b}=9$ \\
\hline \multicolumn{7}{c}{ Spread between spot and futures price $(3$ months $)$} \\
\hline$\hat{r}_{e, 1}$ & $12 / 2008$ & $12 / 2008$ & $12 / 2008$ & $12 / 2008$ & $12 / 2008$ & $12 / 2008$ \\
$\hat{r}_{f, 1}$ & $03 / 2009$ & $01 / 2009$ & $01 / 2009$ & $01 / 2009$ & $01 / 2009$ & $01 / 2009$ \\
\hline \multicolumn{7}{c}{ Spread between spot and futures price $(6$ months $)$} \\
\hline$\hat{r}_{e, 1}$ & $12 / 2008$ & $12 / 2008$ & $12 / 2008$ & $12 / 2008$ & $12 / 2008$ & $12 / 2008$ \\
$\hat{r}_{f, 1}$ & $04 / 2009$ & $04 / 2009$ & $04 / 2009$ & $04 / 2009$ & $04 / 2009$ & $03 / 2009$ \\
\hline \multicolumn{7}{c}{ Spread between spot and futures price $(9$ months $)$} \\
\hline$\hat{r}_{e, 1}$ & $04 / 2001$ & $04 / 2001$ & $10 / 2008$ & $10 / 2008$ & $11 / 2008$ & $12 / 2008$ \\
$\hat{r}_{f, 1}$ & $05 / 2001$ & $05 / 2001$ & $04 / 2009$ & $04 / 2009$ & $04 / 2009$ & $04 / 2009$ \\
\hline$\hat{r}_{e, 2}$ & $10 / 2008$ & $10 / 2008$ & & \\
$\hat{r}_{f, 2}$ & $04 / 2009$ & $04 / 2009$ & & \\
\hline
\end{tabular}

Table 3: The table presents the start $\left(\hat{r}_{e}\right)$ and end dates $\left(\hat{r}_{f}\right)$ of the explosiveness monitoring procedure by Phillips \& Shi (2020) with a significance level of $\alpha=0.05$ applied to monthly $(07 / 1983$ to $12 / 2014)$ spreads between spot and futures prices. The size controlling parameter $\tau_{b}$ varies from four to nine. 


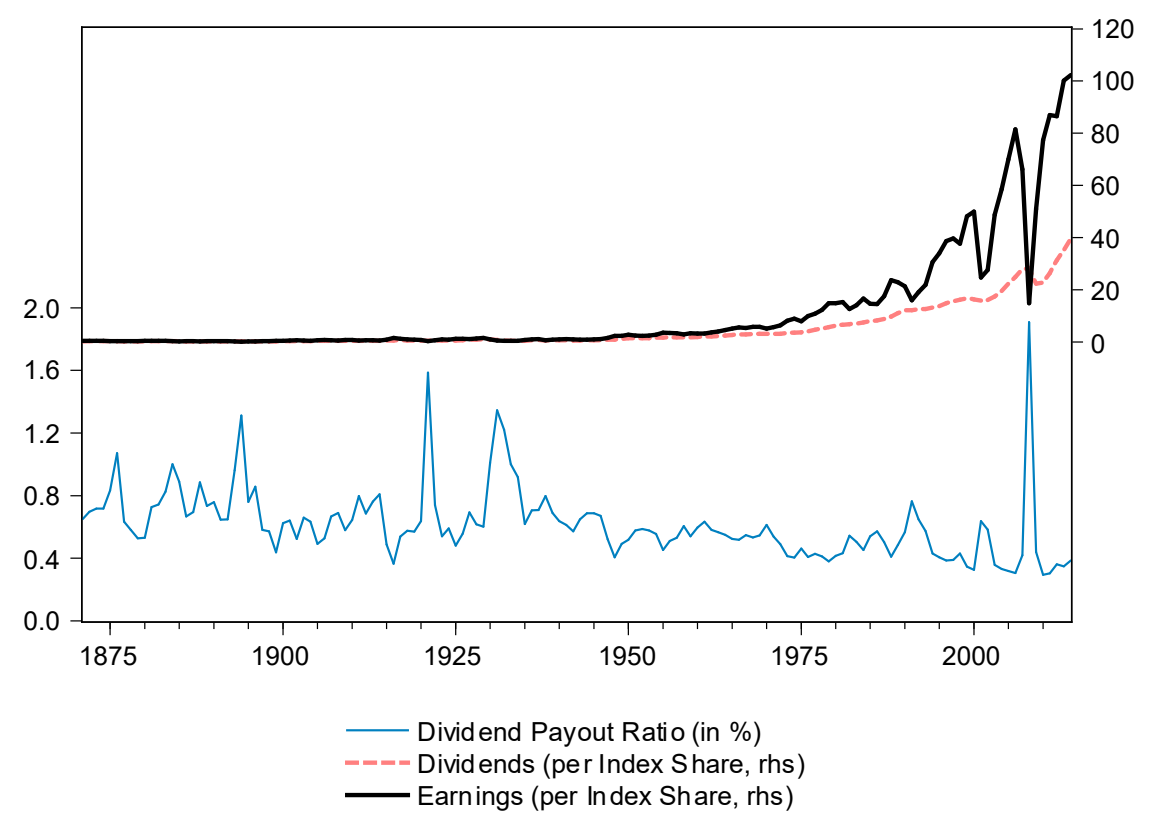

Figure 1: The figure shows the dividends per index share and the earnings per index share of the S\&P 500 (respectively its predecessors) as well as the dividend payout ratio.

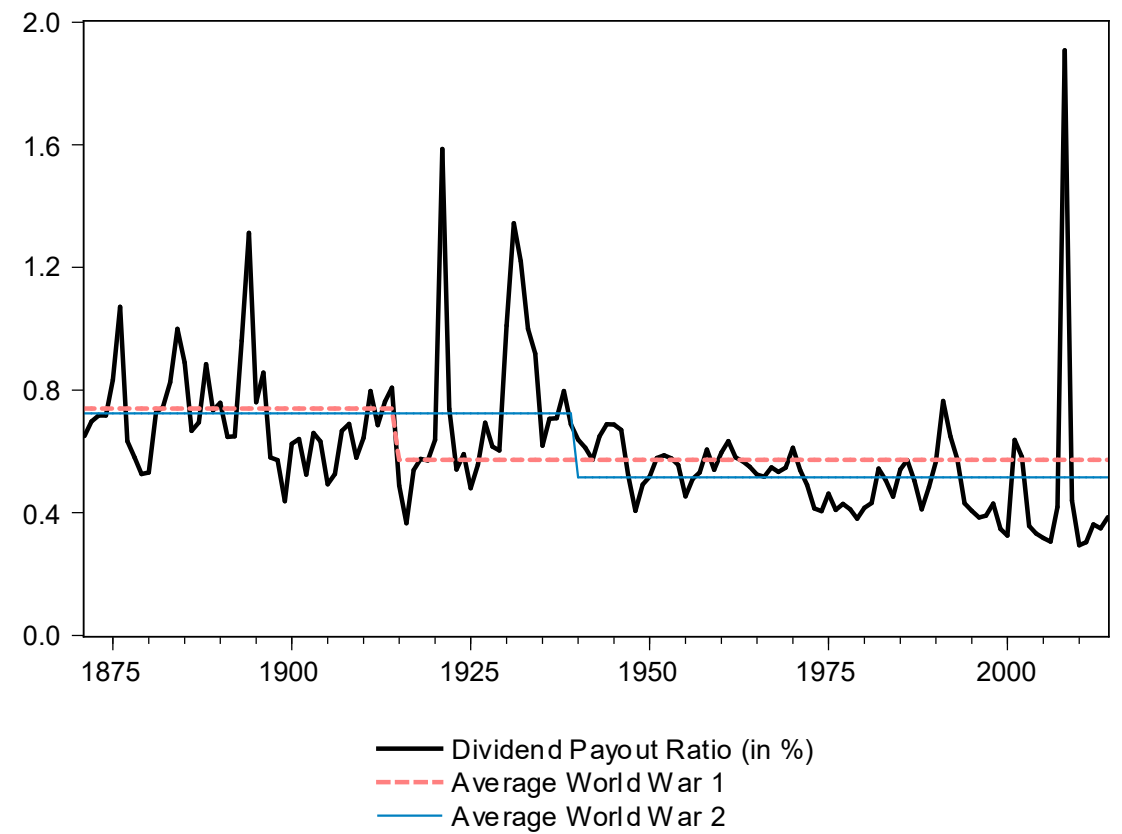

Figure 2: This figure displays the historical data on the dividend payout ratio examining the S\&P 500 equity index and its predecessors as well as the average dividend payout ratio before and during/after World War 1 (respectively World War 2). 


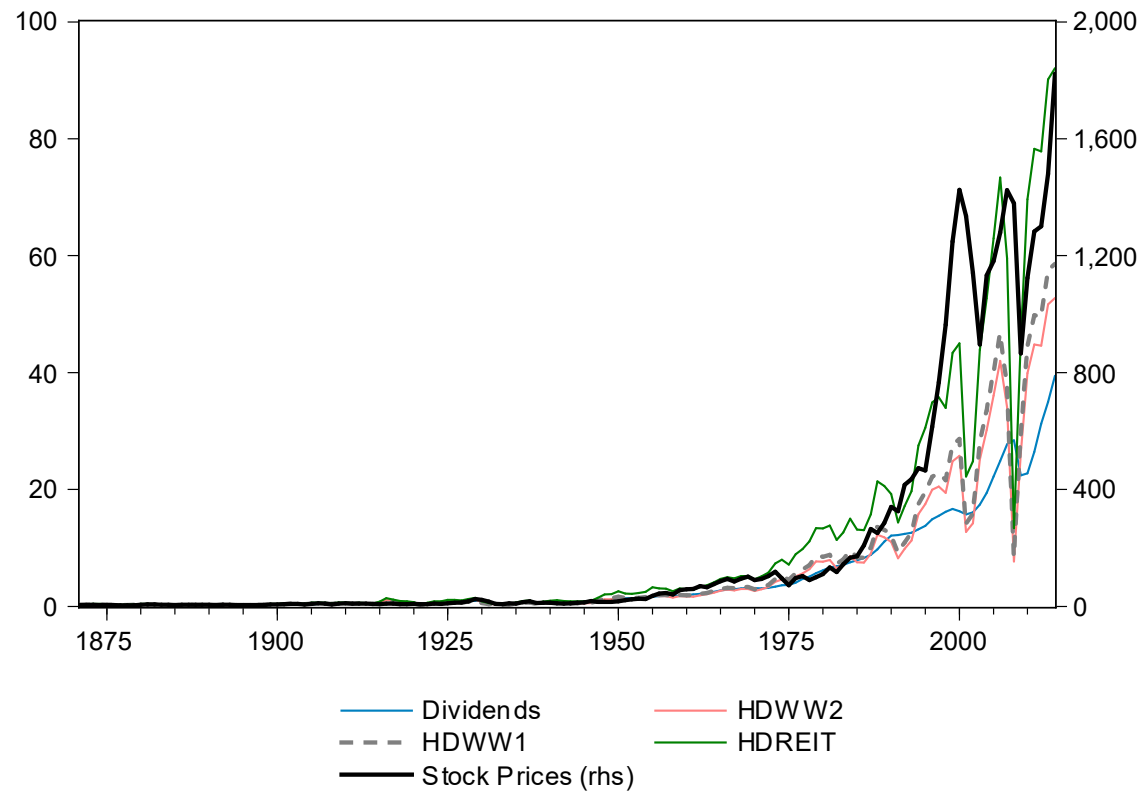

Figure 3: The figure shows stock prices and dividends (per index share) of the S\&P 500 equity index and its predecessors as well as three "hypothetical" dividend time series calculated from corporate earnings.

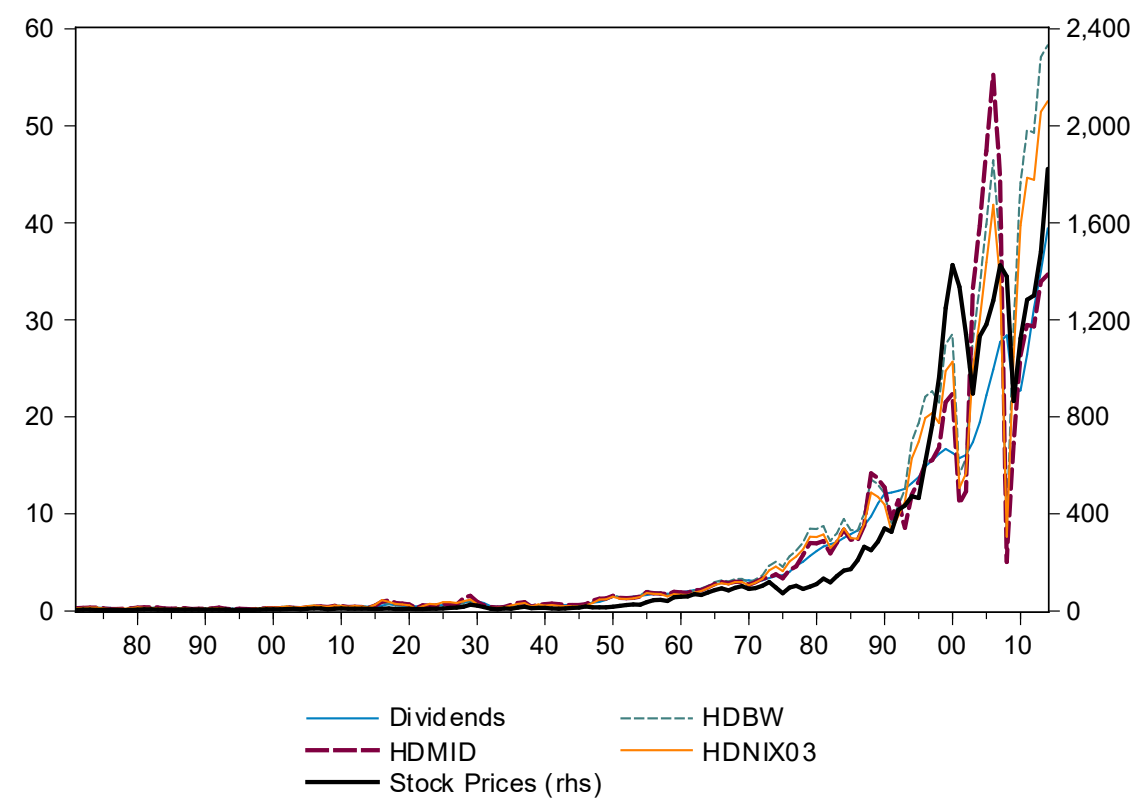

Figure 4: This figure displays stock prices (S\&P 500 equity index and its predecessors) and three "hypothetical" dividend time series constructed from corporate earnings. 


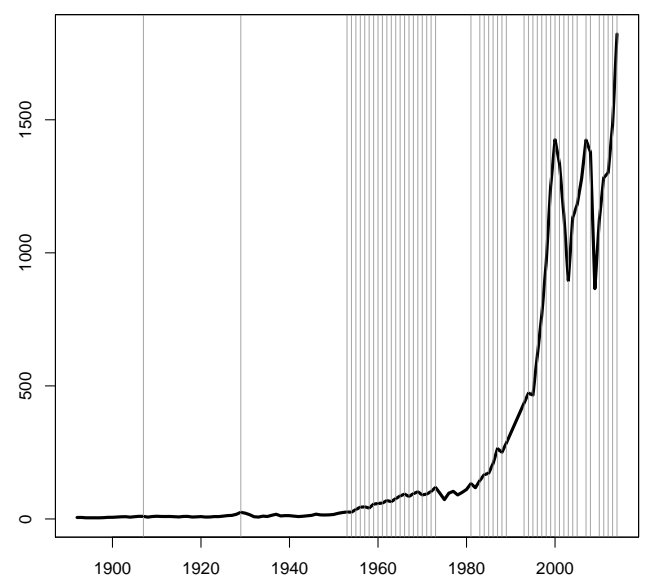

(a) $\tau_{b}=4$

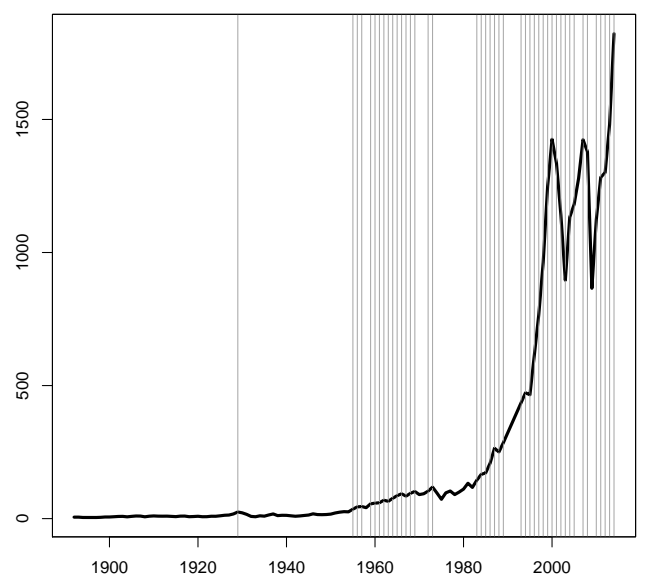

(c) $\tau_{b}=6$.

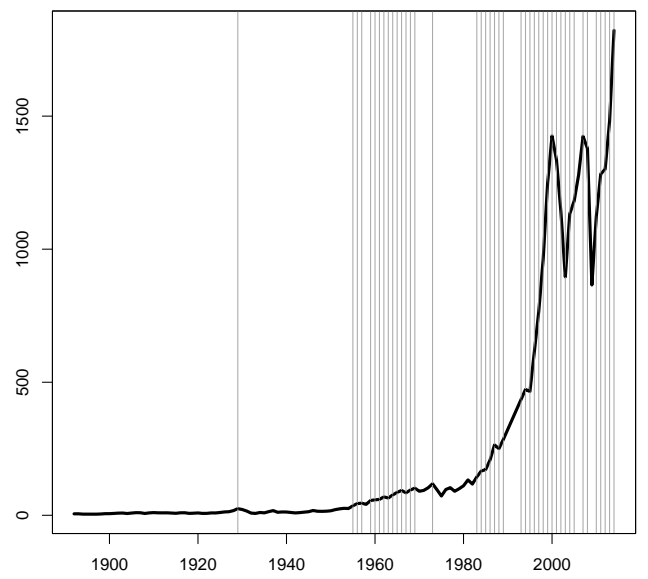

(e) $\tau_{b}=8$.

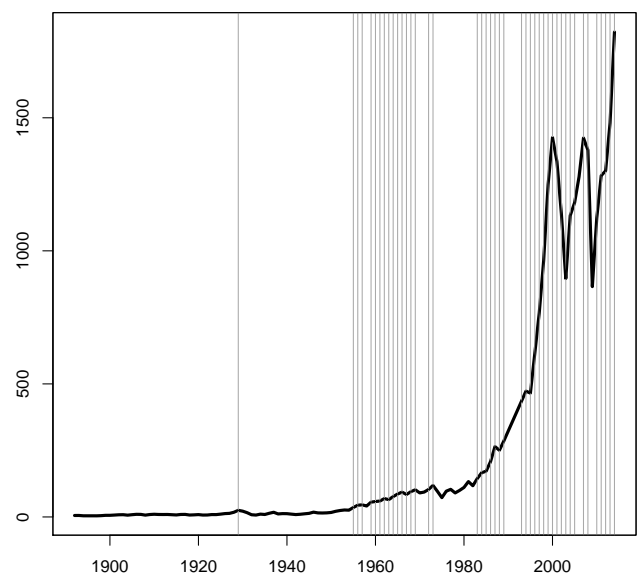

(b) $\tau_{b}=5$.

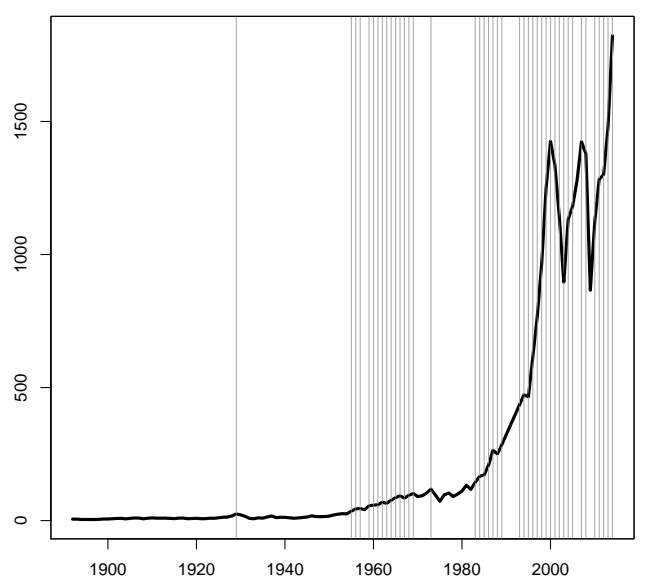

(d) $\tau_{b}=7$.

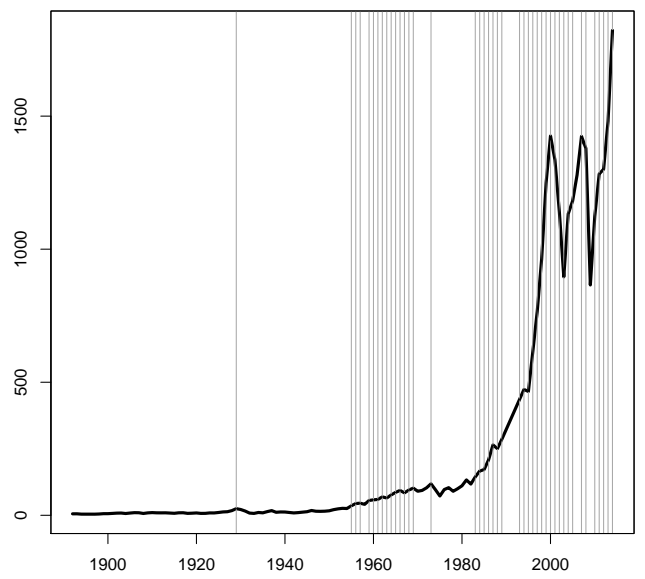

(f) $\tau_{b}=9$.

Figure 5: The figures present the trajectories of the yearly price series with the corresponding results of the pseudo real-time monitoring proposed by Phillips \& Shi (2020) for a significance level of $\alpha=0.05$. The size control parameter $\tau_{b}$ increases from the left upper figure to the right figure at the bottom from four to nine by steps of one. The number of lags in the Augmented Dickey Fuller regression (see Equation (7)) is selected by the $B I C$. Gray shaded areas indicate explosive periods. 


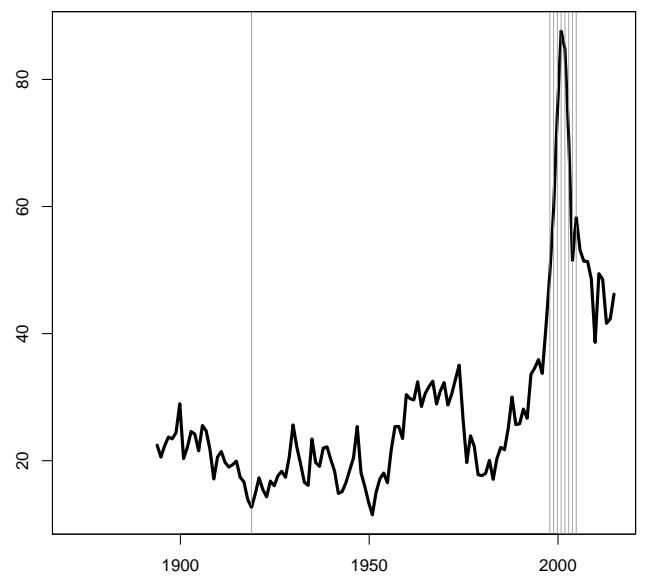

(a) $\tau_{b}=4$.

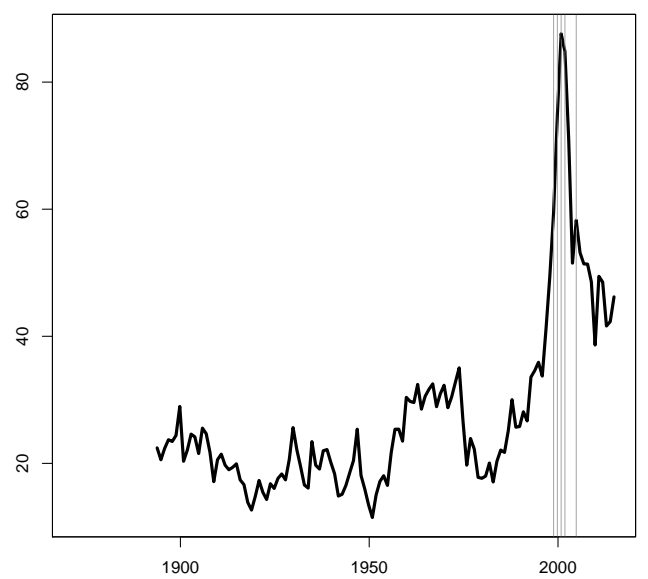

(c) $\tau_{b}=6$.

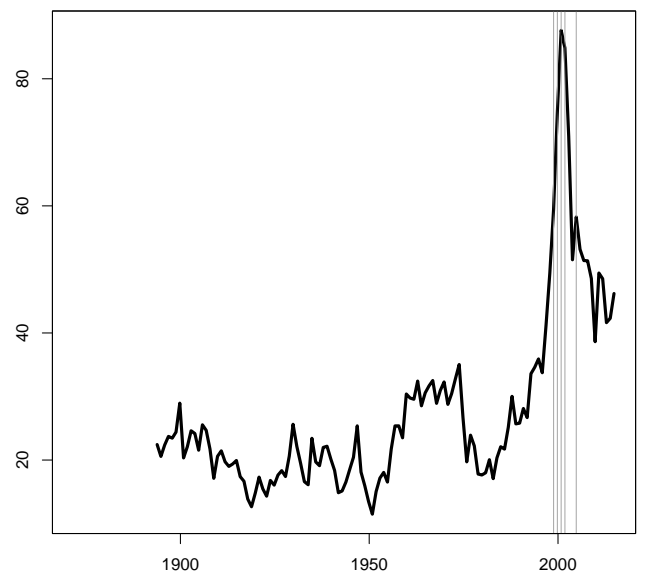

(e) $\tau_{b}=8$.

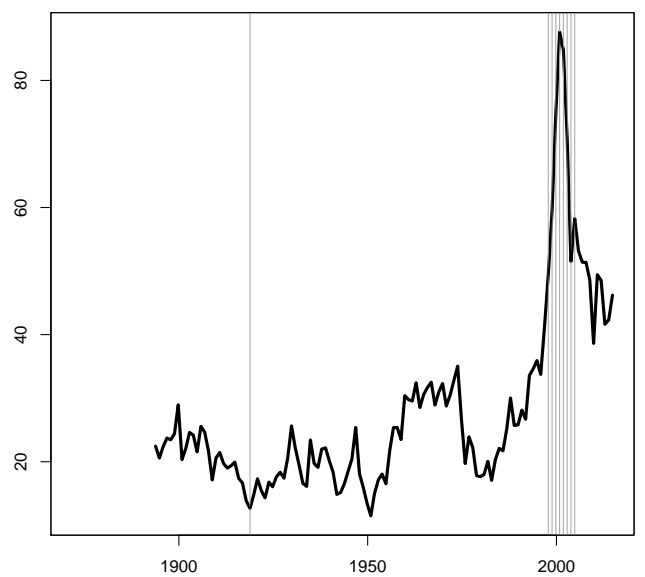

(b) $\tau_{b}=5$.

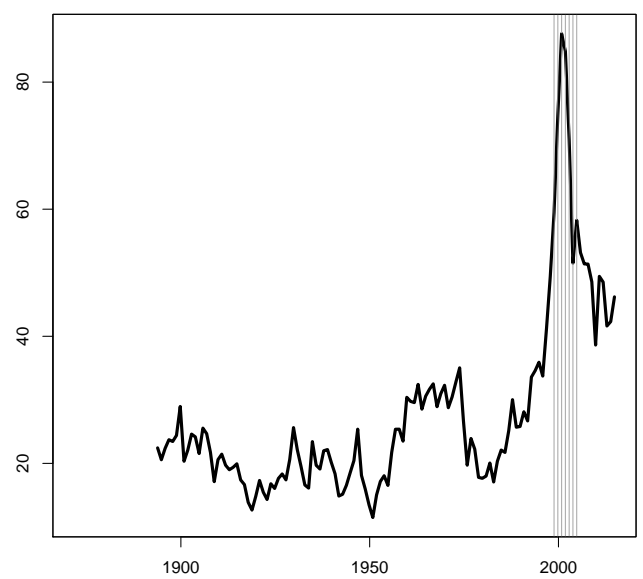

(d) $\tau_{b}=7$.

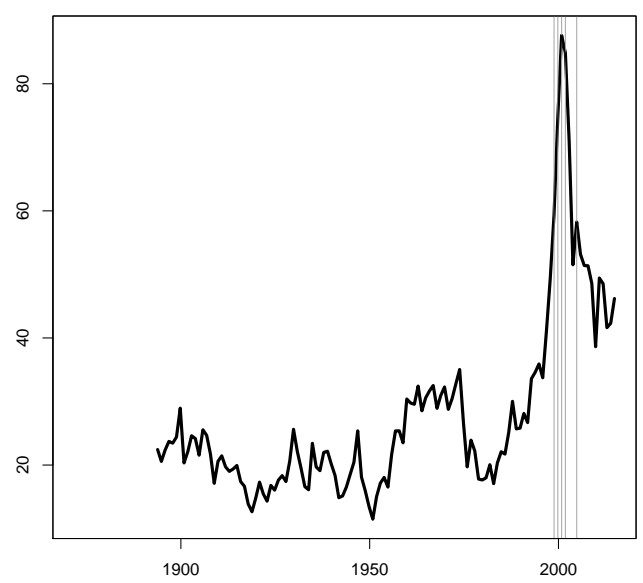

(f) $\tau_{b}=9$.

Figure 6: The figures present the trajectories of the yearly price-dividend ratio with the corresponding results of the pseudo real-time monitoring proposed by Phillips \& Shi $(2020)$ for a significance level of $\alpha=0.05$. The size control parameter $\tau_{b}$ increases from the left upper figure to the right figure at the bottom from four to nine by steps of one. The number of lags in the Augmented Dickey Fuller regression (see Equation (7) ) is selected by the BIC. Gray shaded areas indicate explosive periods. 


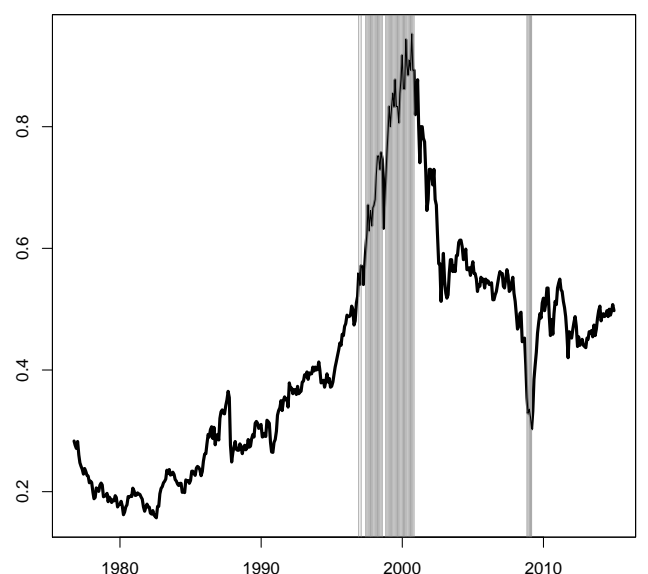

(a) $\tau_{b}=4$.

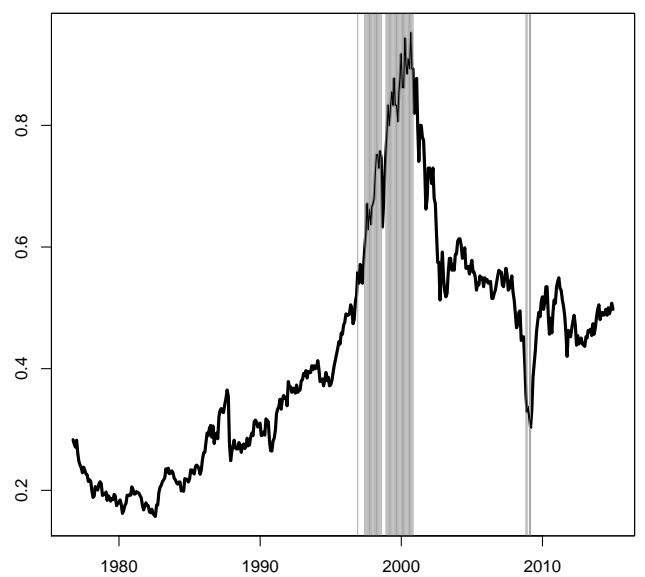

(c) $\tau_{b}=6$.

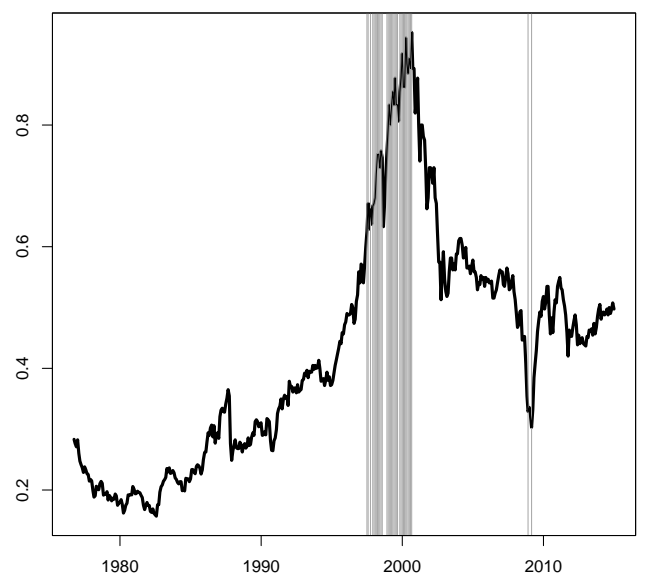

(e) $\tau_{b}=8$.

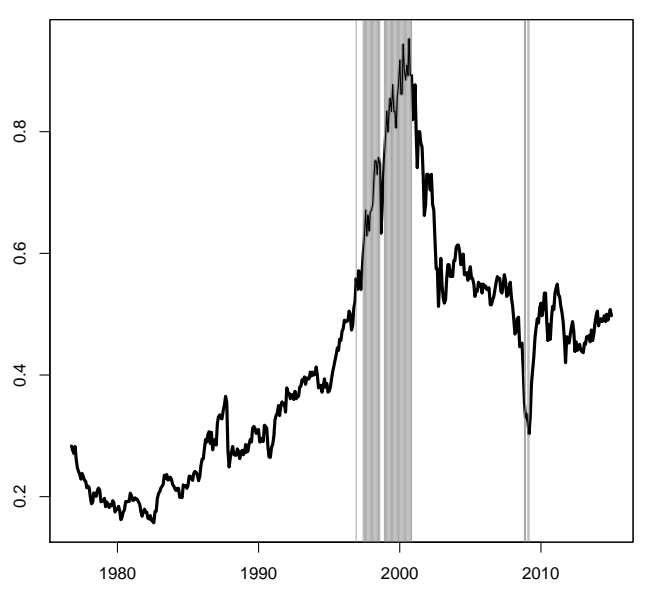

(b) $\tau_{b}=5$

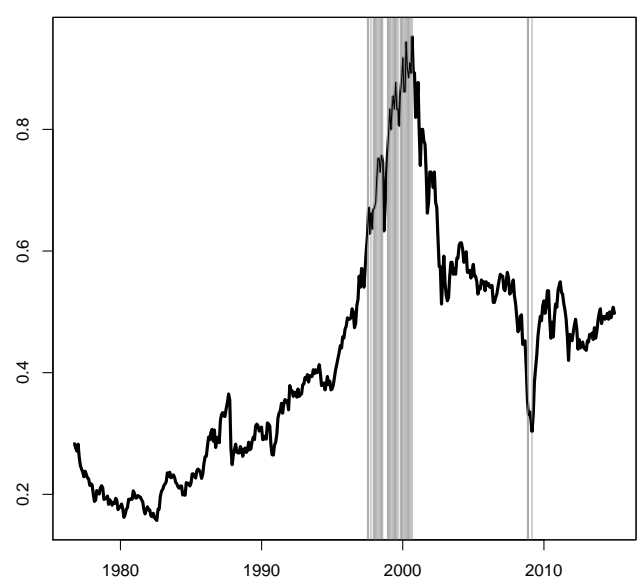

(d) $\tau_{b}=7$

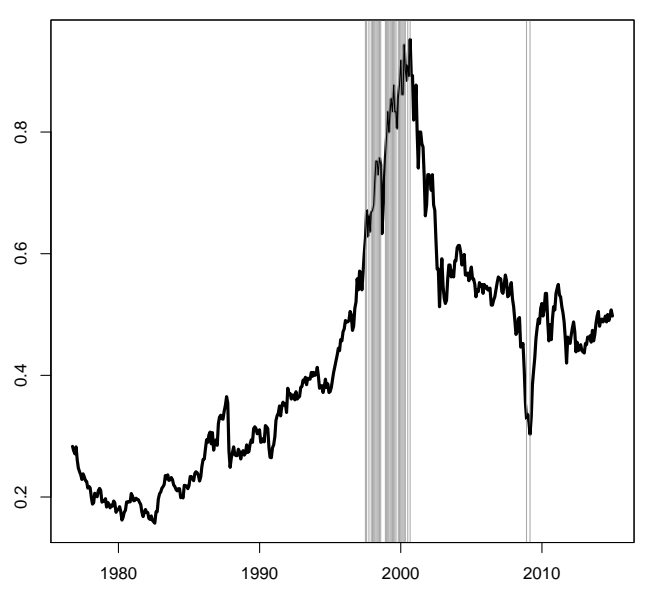

(f) $\tau_{b}=9$.

Figure 7: The figures present the trajectories of the monthly price-dividend ratio with the corresponding results of the pseudo real-time monitoring proposed by Phillips \& Shi $(2020)$ for a significance level of $\alpha=0.05$. The size control parameter $\tau_{b}$ increases from the left upper figure to the right figure at the bottom from four to nine by steps of one. The number of lags in the Augmented Dickey Fuller regression (see Equation (7) ) is selected by the BIC. Gray shaded areas indicate explosive periods. 


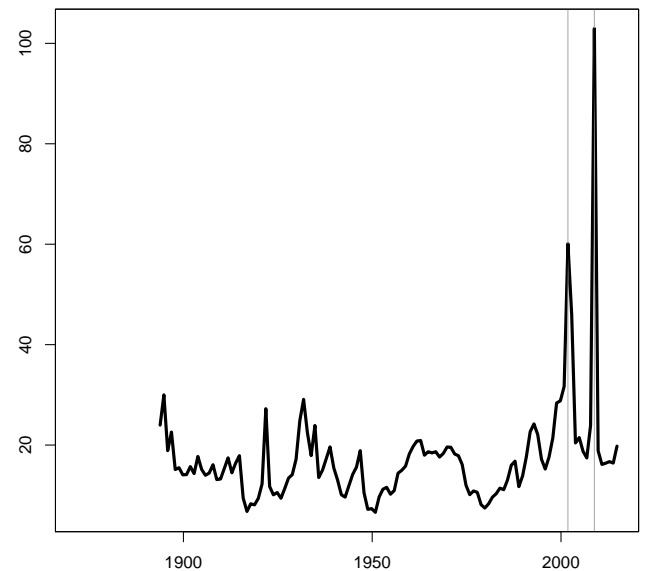

(a) $\tau_{b}=4$.

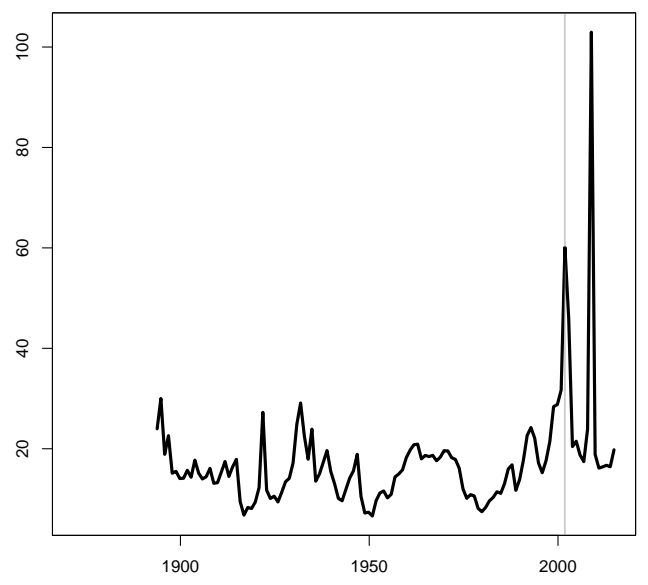

(c) $\tau_{b}=6$.

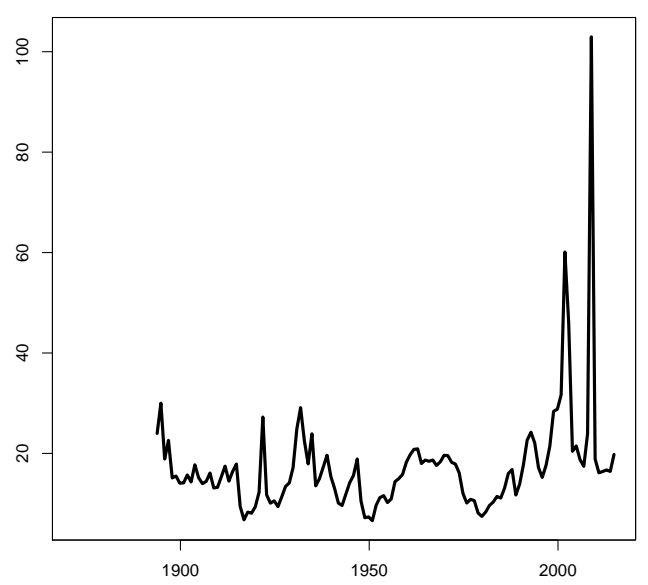

(e) $\tau_{b}=8$.

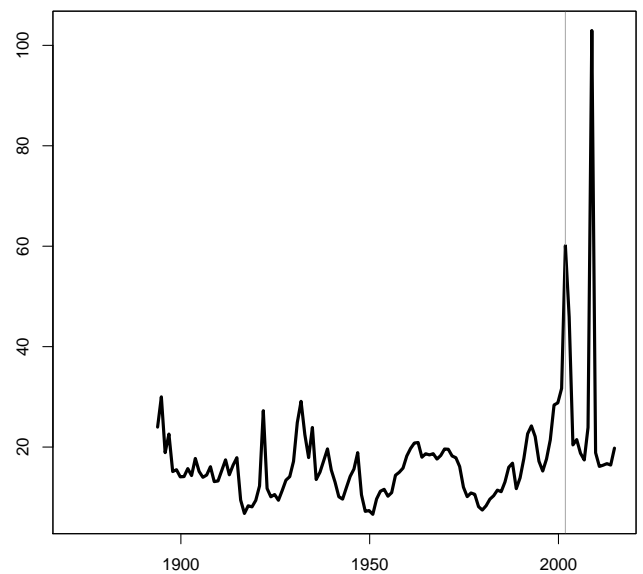

(b) $\tau_{b}=5$.

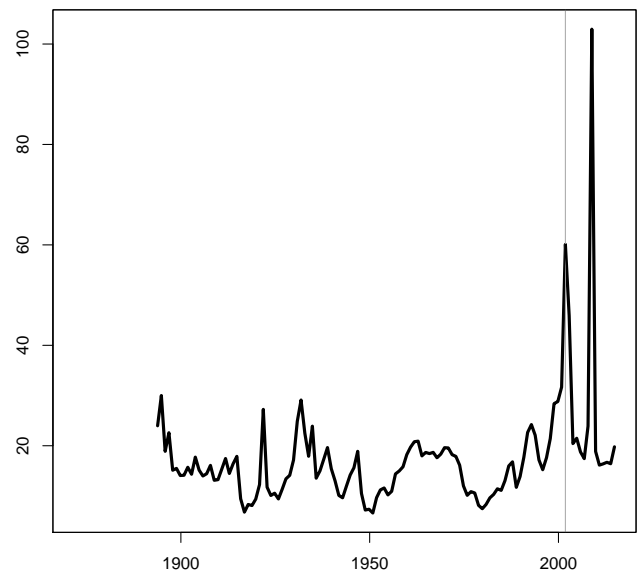

(d) $\tau_{b}=7$.

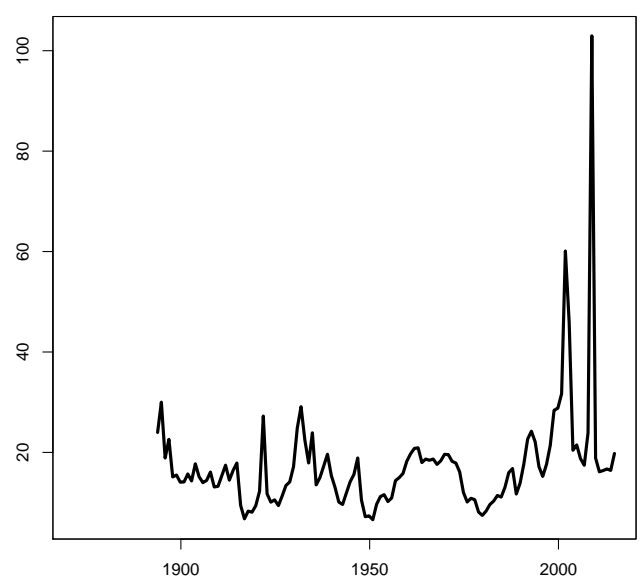

(f) $\tau_{b}=9$.

Figure 8: The figures present the trajectories of the ratio of the price and the dividend proxy HDREIT with the corresponding results of the pseudo real-time monitoring proposed by Phillips \& Shi (2020) for a significance level of $\alpha=0.05$. The size control parameter $\tau_{b}$ increases from the left upper figure to the right figure at the bottom from four to nine by steps of one. The number of lags in the Augmented Dickey Fuller regression (see Equation (7)) is selected by the $B I C$. Gray shaded areas indicate explosive periods. 


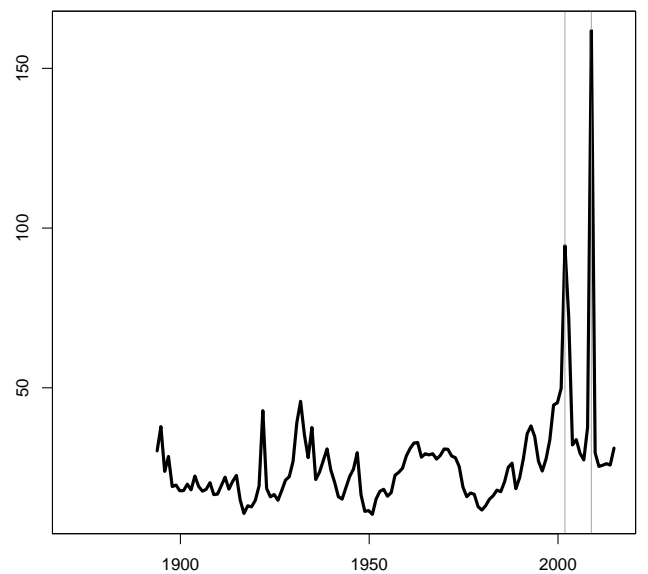

(a) $\tau_{b}=4$.

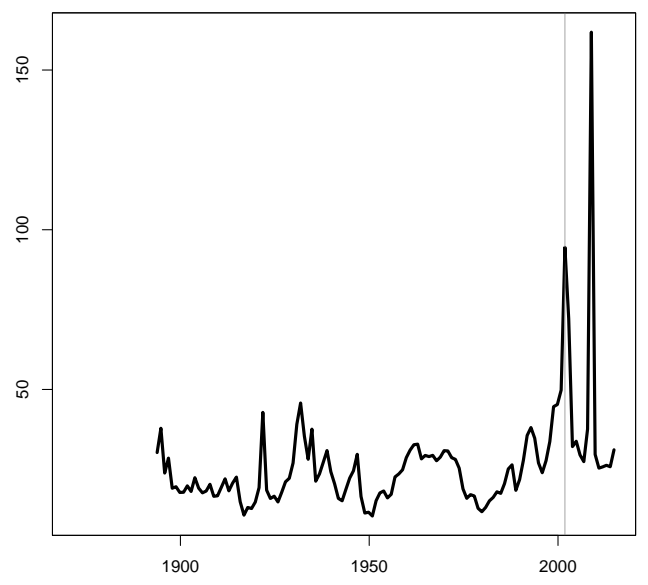

(c) $\tau_{b}=6$.

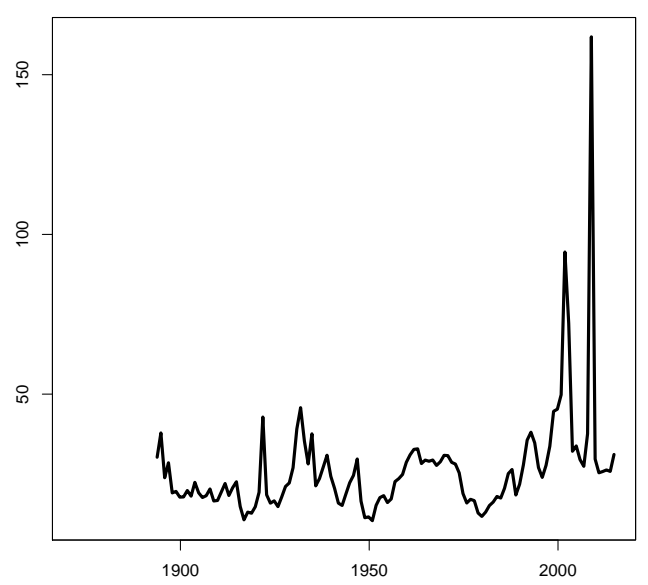

(e) $\tau_{b}=8$.

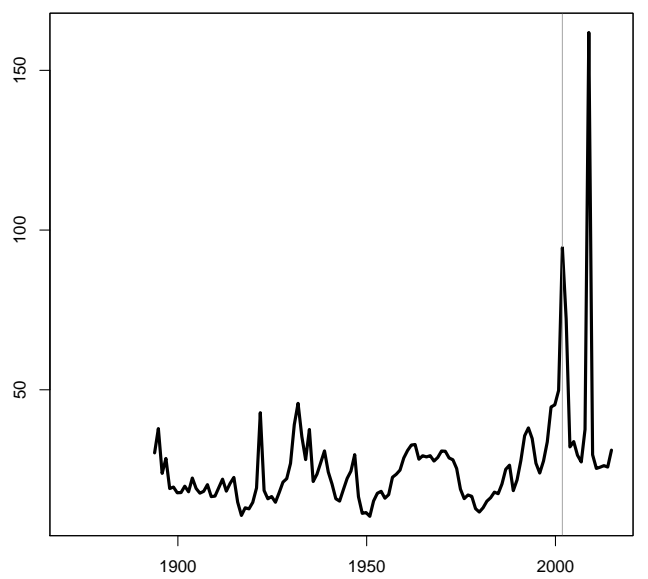

(b) $\tau_{b}=5$.

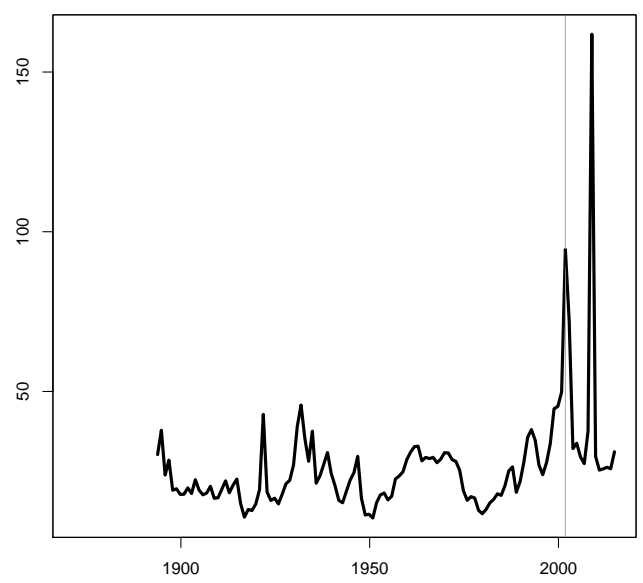

(d) $\tau_{b}=7$.

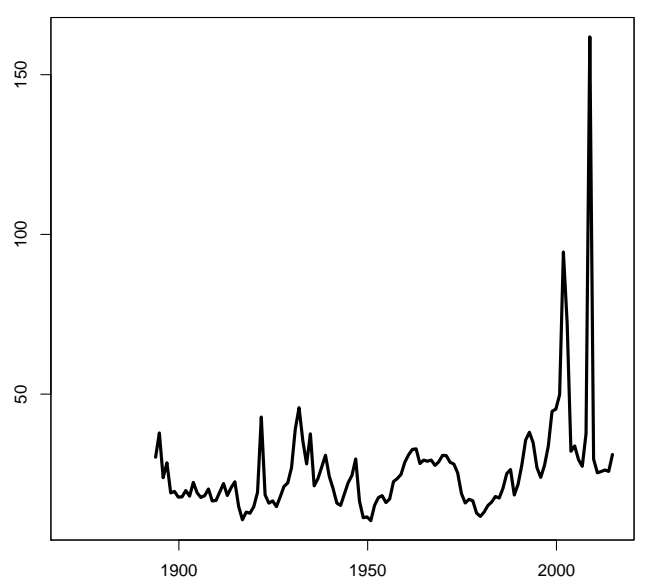

(f) $\tau_{b}=9$.

Figure 9: The figures present the trajectories of the ratio of the price and the dividend proxy $H D W W 1$ with the corresponding results of the pseudo real-time monitoring proposed by Phillips \& Shi (2020) for a significance level of $\alpha=0.05$. The size control parameter $\tau_{b}$ increases from the left upper figure to the right figure at the bottom from four to nine by steps of one. The number of lags in the Augmented Dickey Fuller regression (see Equation (7)) is selected by the $B I C$. Gray shaded areas indicate explosive periods. 


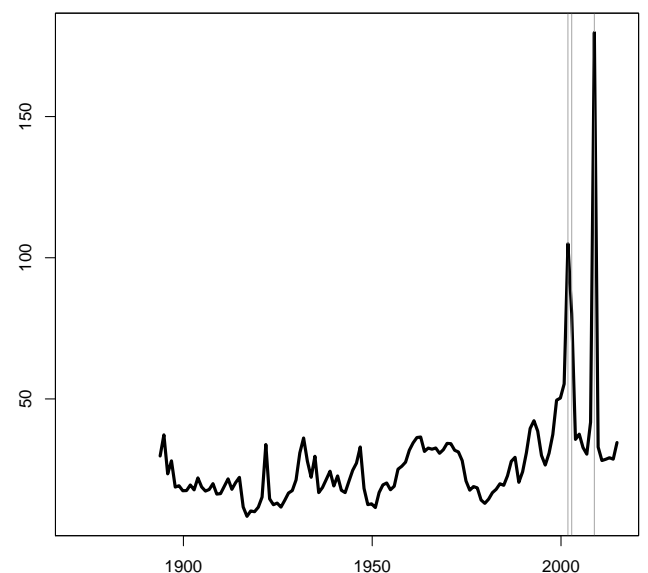

(a) $\tau_{b}=4$.

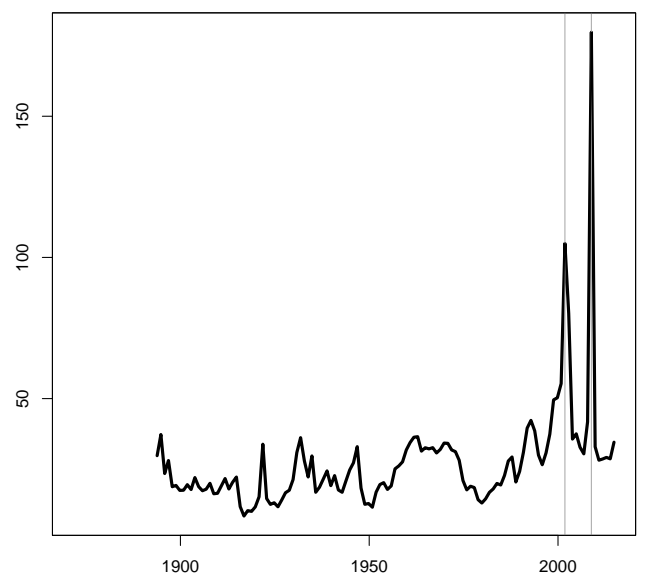

(c) $\tau_{b}=6$.

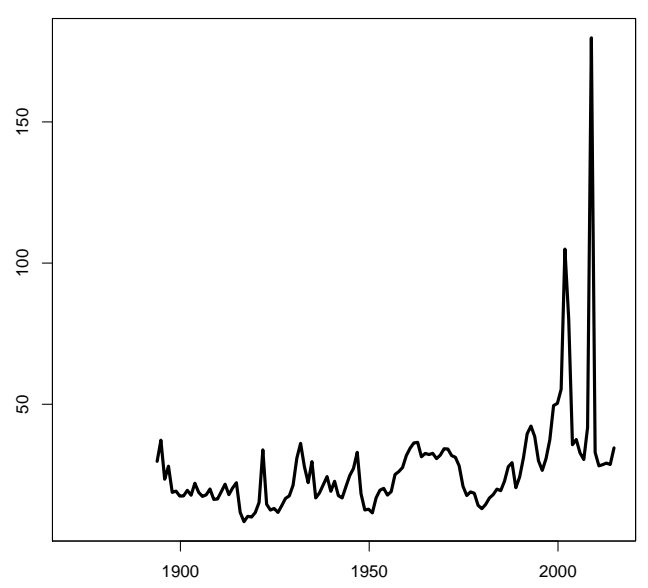

(e) $\tau_{b}=8$.

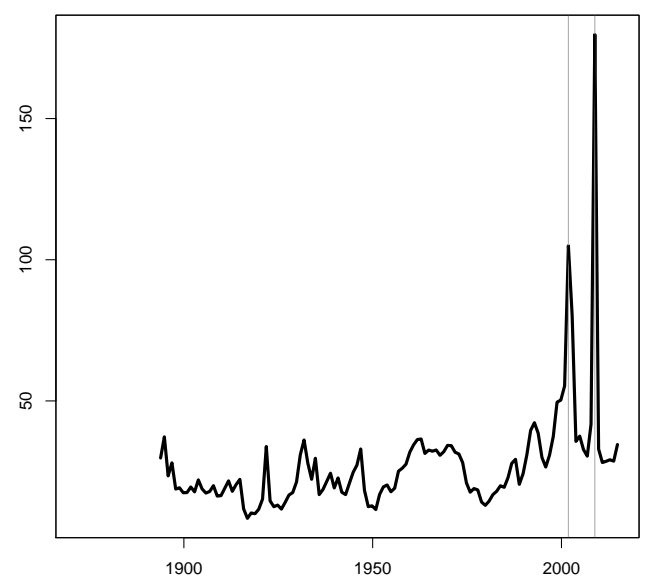

(b) $\tau_{b}=5$.

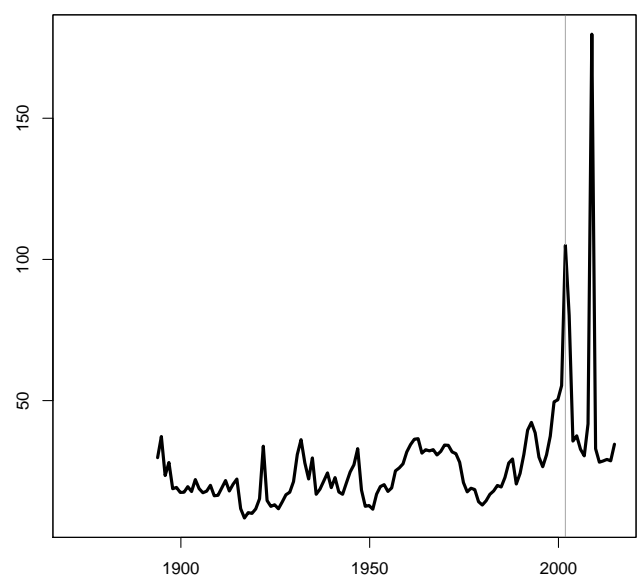

(d) $\tau_{b}=7$.

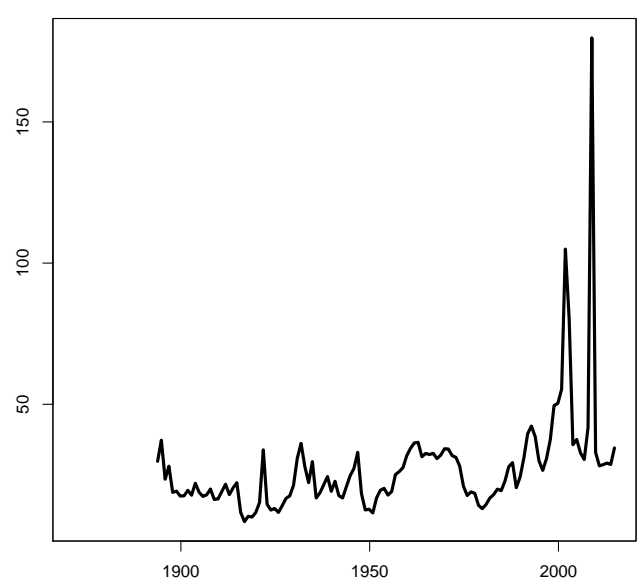

(f) $\tau_{b}=9$.

Figure 10: The figures present the trajectories of the ratio of the price and the dividend proxy $H D W W 2$ with the corresponding results of the pseudo real-time monitoring proposed by Phillips \& Shi (2020) for a significance level of $\alpha=0.05$. The size control parameter $\tau_{b}$ increases from the left upper figure to the right figure at the bottom from four to nine by steps of one. The number of lags in the Augmented Dickey Fuller regression (see Equation (7)) is selected by the BIC. Gray shaded areas indicate explosive periods. 


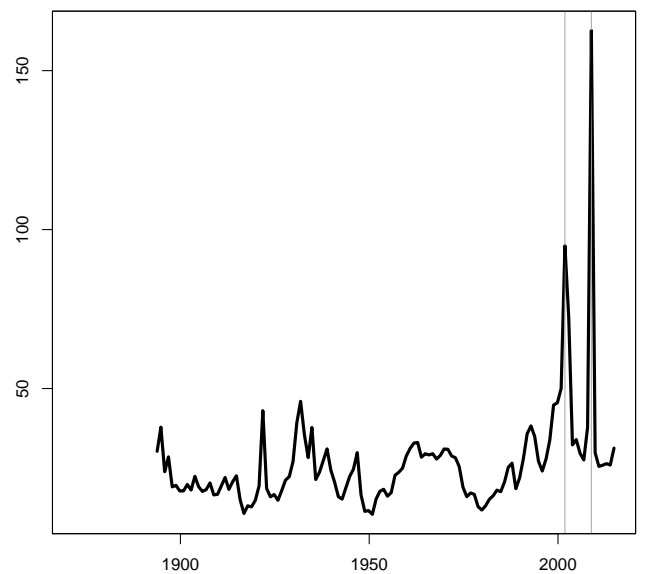

(a) $\tau_{b}=4$.

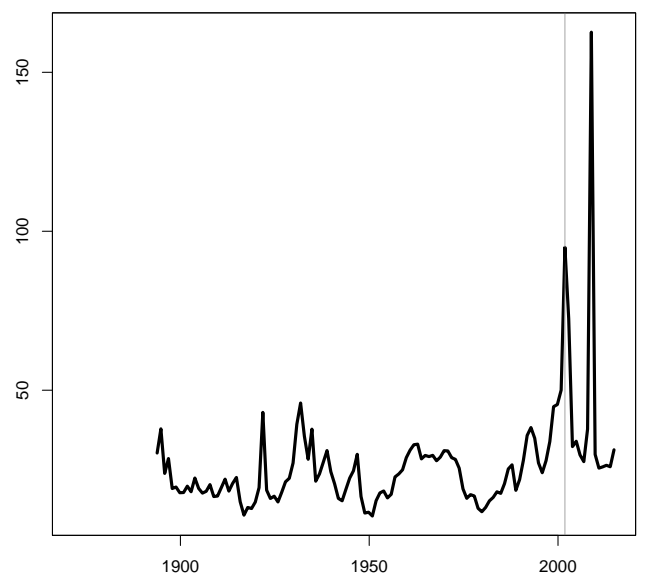

(c) $\tau_{b}=6$.

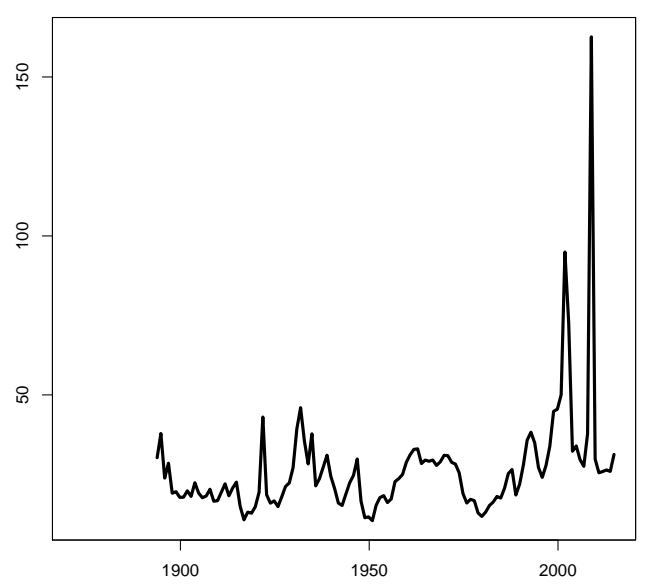

(e) $\tau_{b}=8$.

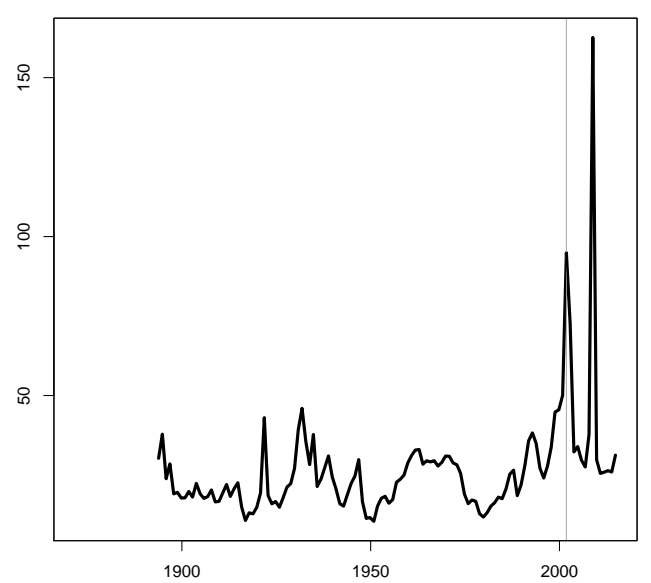

(b) $\tau_{b}=5$.

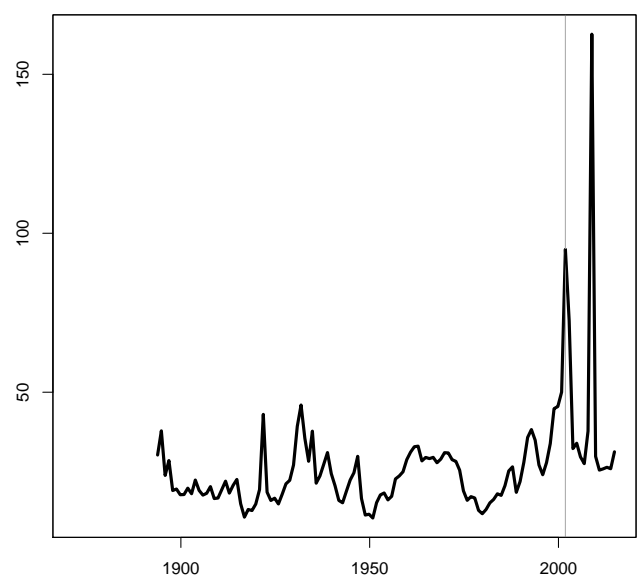

(d) $\tau_{b}=7$.

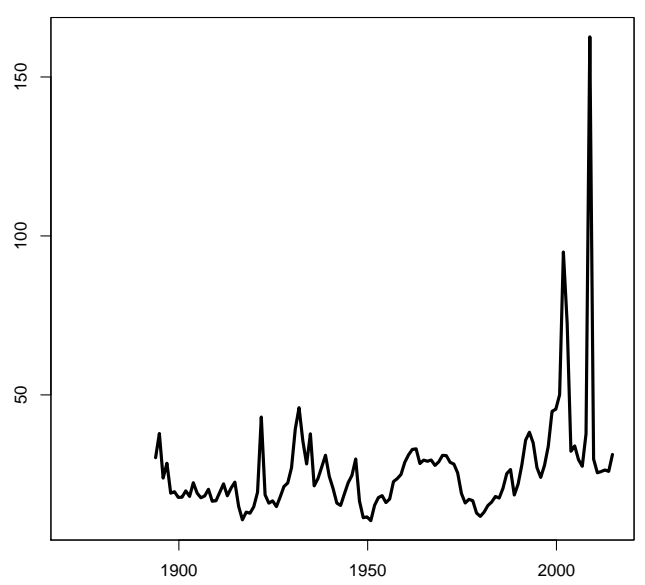

(f) $\tau_{b}=9$.

Figure 11: The figures present the trajectories of the ratio of the price and the dividend proxy $H D B W$ with the corresponding results of the pseudo real-time monitoring proposed by Phillips \& Shi (2020) for a significance level of $\alpha=0.05$. The size control parameter $\tau_{b}$ increases from the left upper figure to the right figure at the bottom from four to nine by steps of one. The number of lags in the Augmented Dickey Fuller regression (see Equation (7)) is selected by the $B I C$. Gray shaded areas indicate explosive periods. 


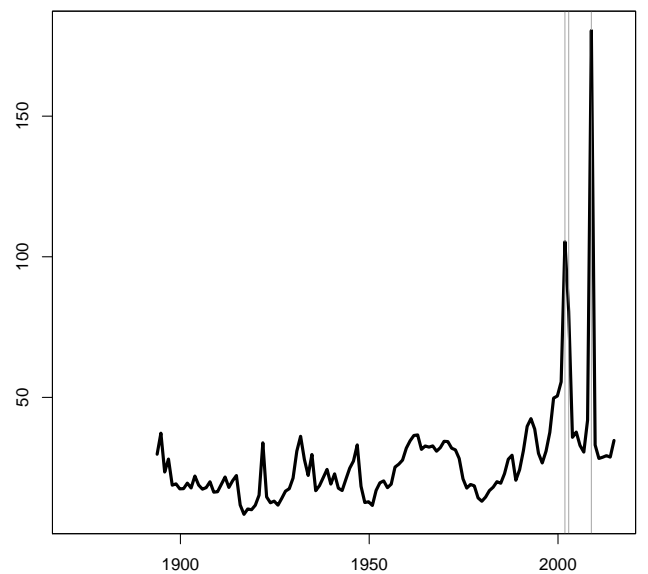

(a) $\tau_{b}=4$.

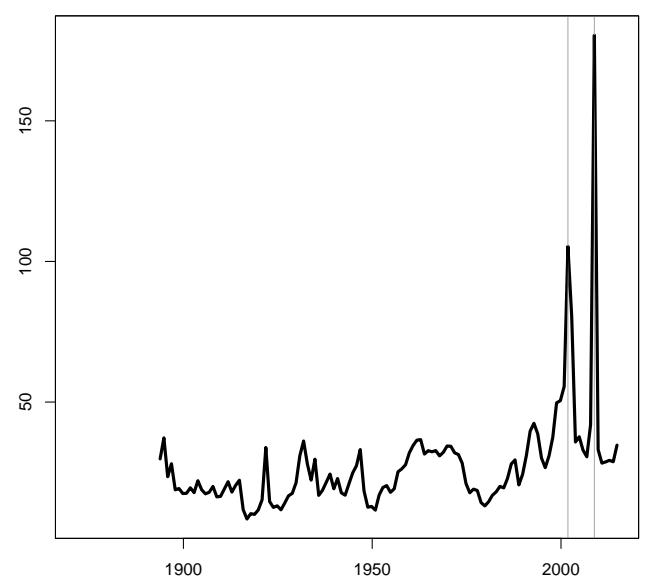

(c) $\tau_{b}=6$.

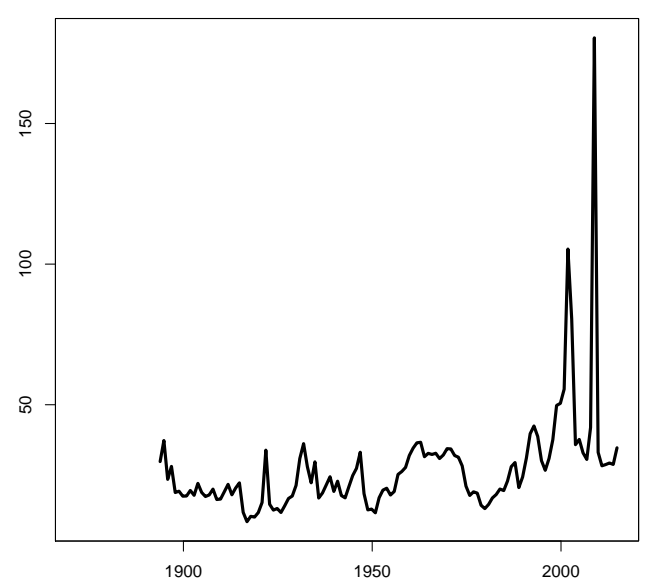

(e) $\tau_{b}=8$.

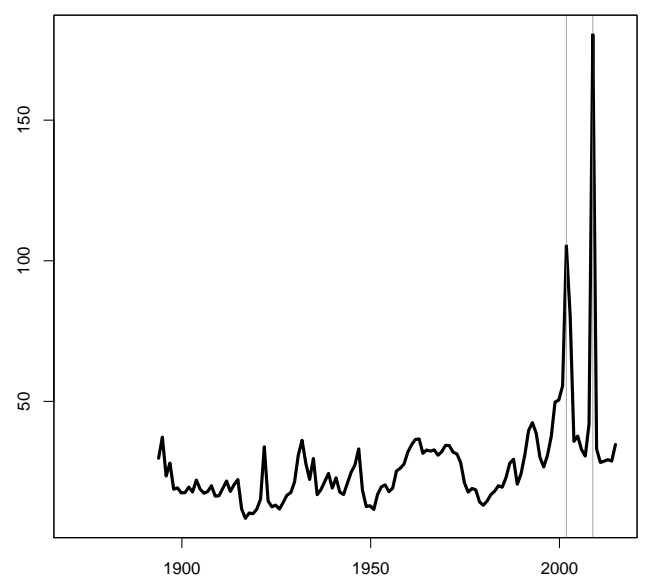

(b) $\tau_{b}=5$.

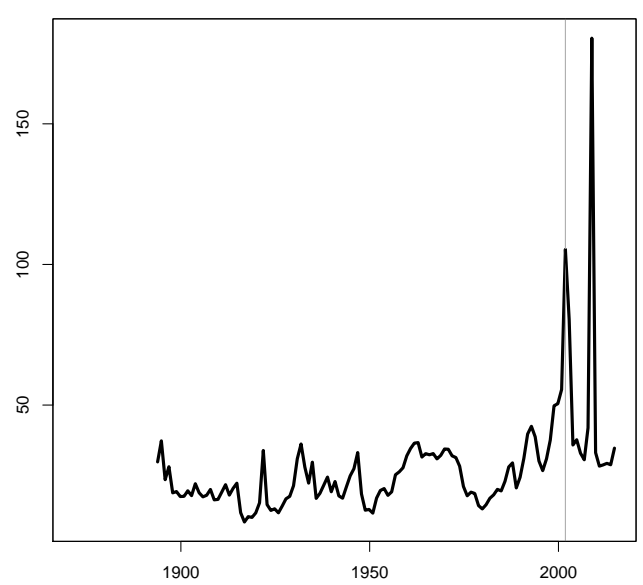

(d) $\tau_{b}=7$.

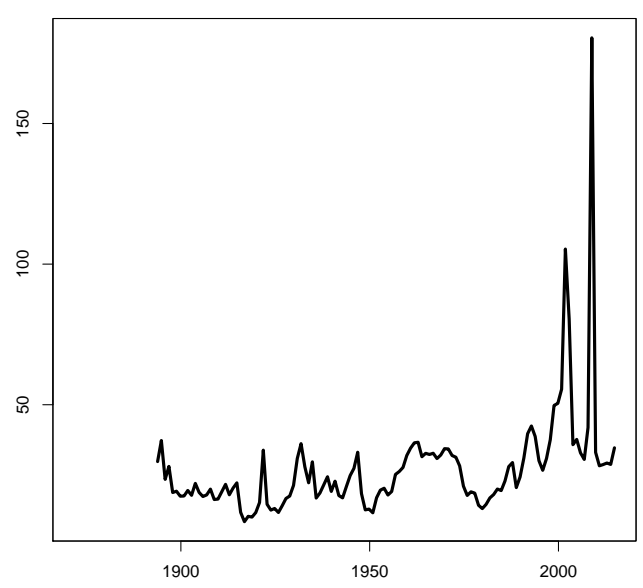

(f) $\tau_{b}=9$.

Figure 12: The figures present the trajectories of the ratio of the price and the dividend proxy HDNIX03 with the corresponding results of the pseudo real-time monitoring proposed by Phillips \& Shi (2020) for a significance level of $\alpha=0.05$. The size control parameter $\tau_{b}$ increases from the left upper figure to the right figure at the bottom from four to nine by steps of one. The number of lags in the Augmented Dickey Fuller regression (see Equation (7)) is selected by the $B I C$. Gray shaded areas indicate explosive periods. 


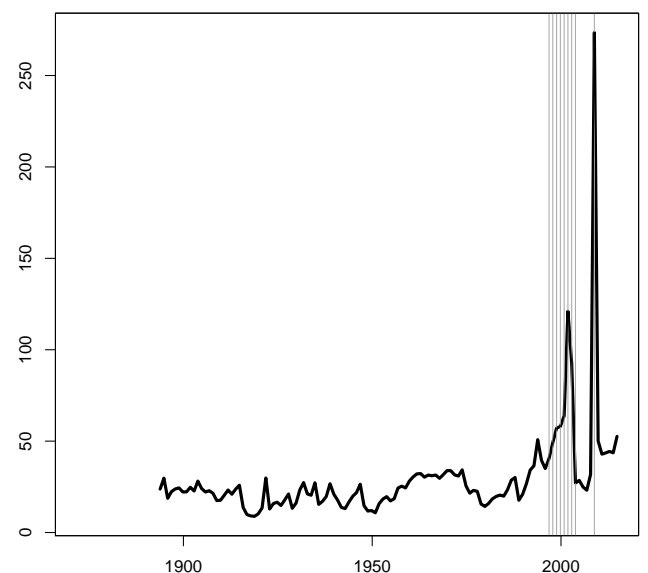

(a) $\tau_{b}=4$.

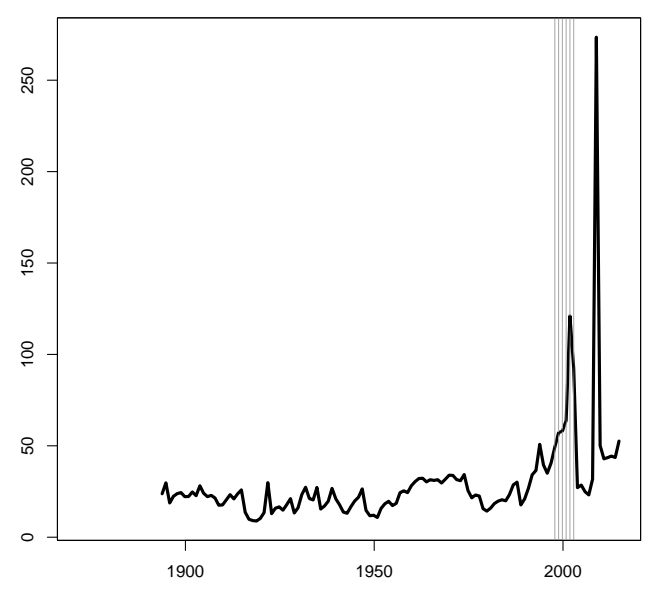

(c) $\tau_{b}=6$.

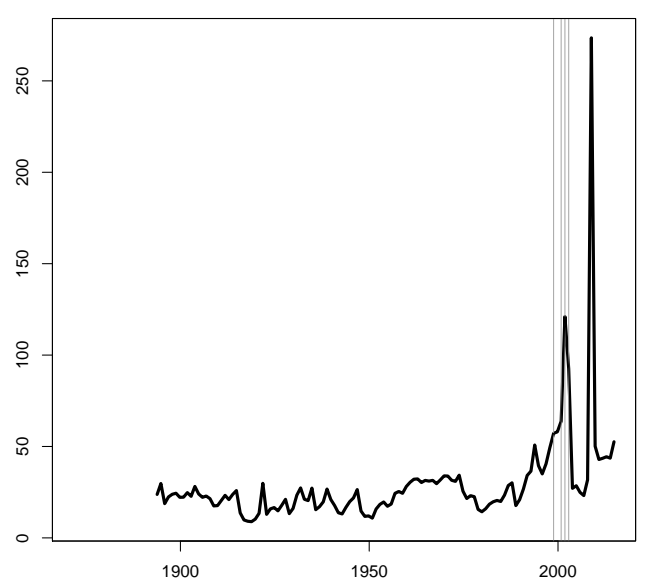

(e) $\tau_{b}=8$.

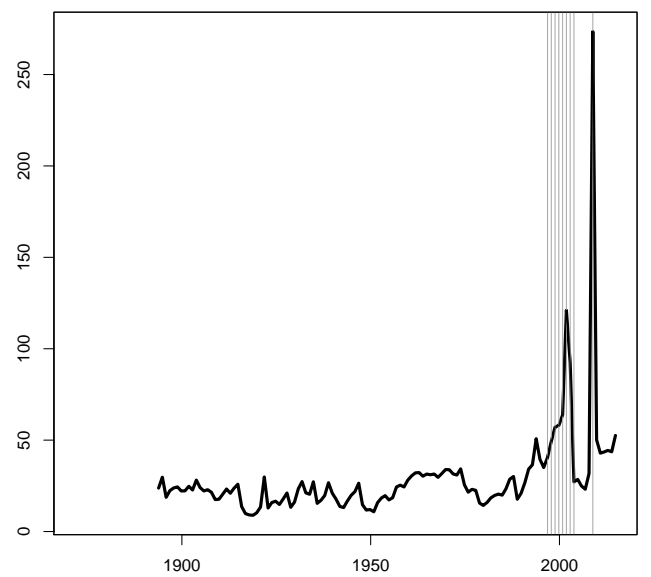

(b) $\tau_{b}=5$.

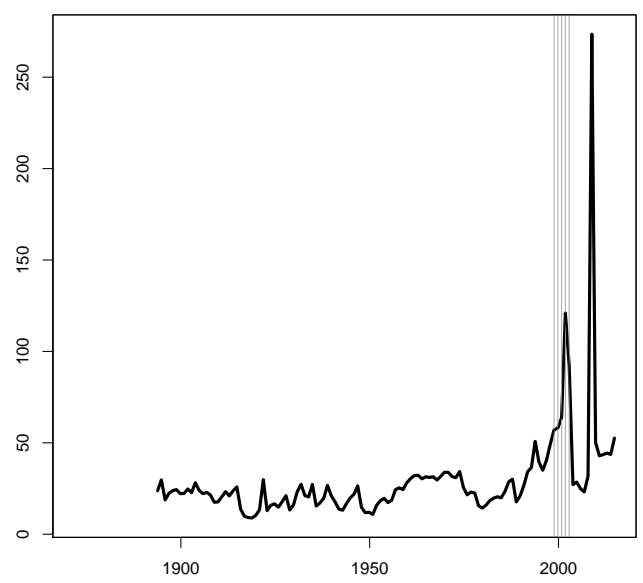

(d) $\tau_{b}=7$.

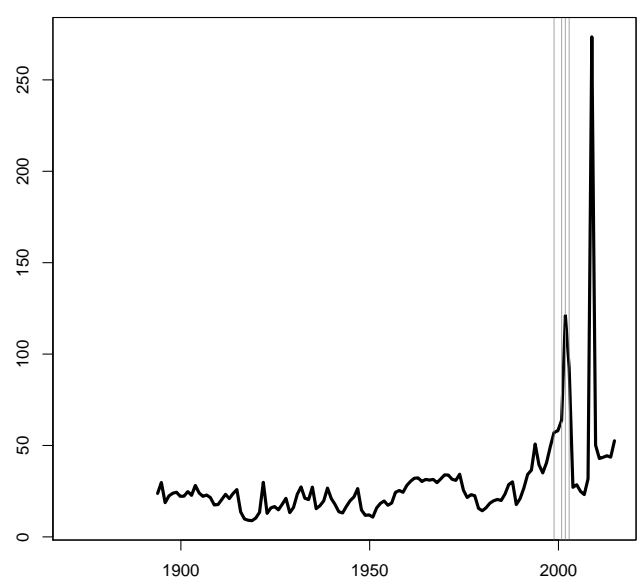

(f) $\tau_{b}=9$.

Figure 13: The figures present the trajectories of the ratio of the price and the dividend proxy $H D M I D$ with the corresponding results of the pseudo real-time monitoring proposed by Phillips \& Shi (2020) for a significance level of $\alpha=0.05$. The size control parameter $\tau_{b}$ increases from the left upper figure to the right figure at the bottom from four to nine by steps of one. The number of lags in the Augmented Dickey Fuller regression (see Equation (7)) is selected by the $B I C$. Gray shaded areas indicate explosive periods. 


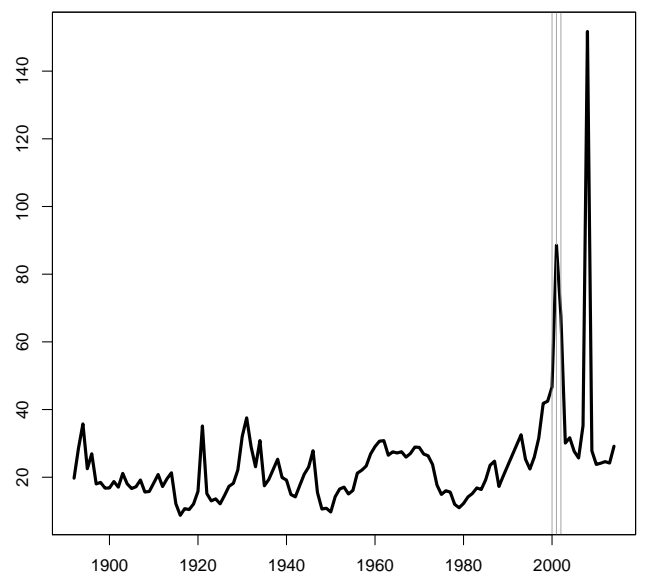

(a) $\tau_{b}=4$.

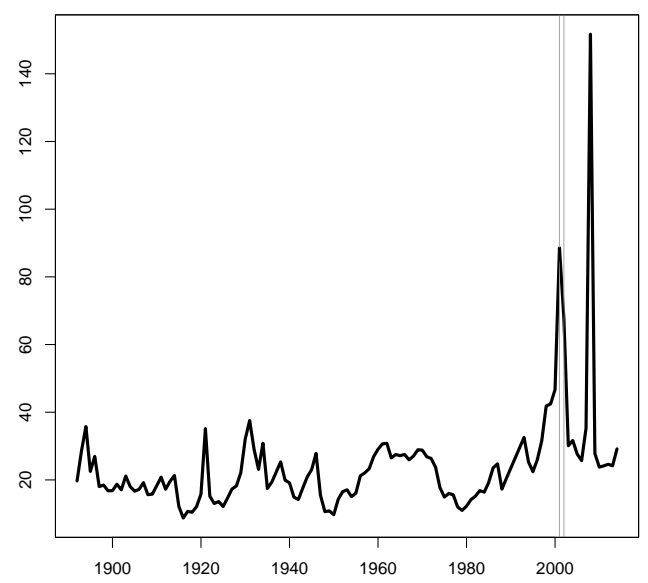

(c) $\tau_{b}=6$.

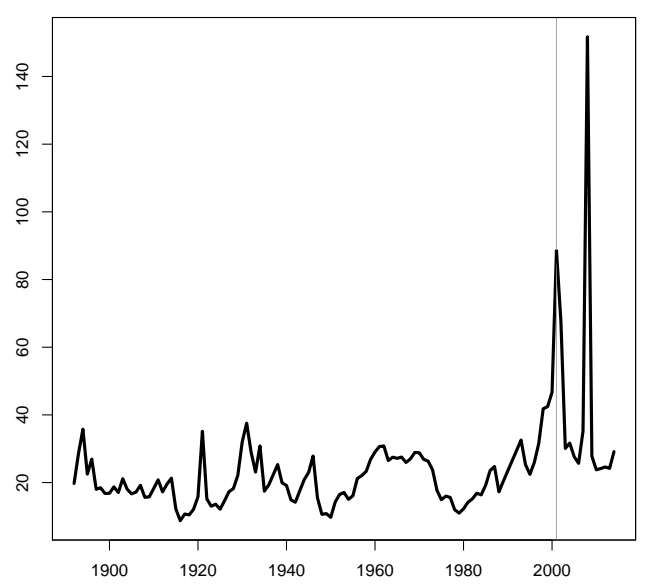

(e) $\tau_{b}=8$.

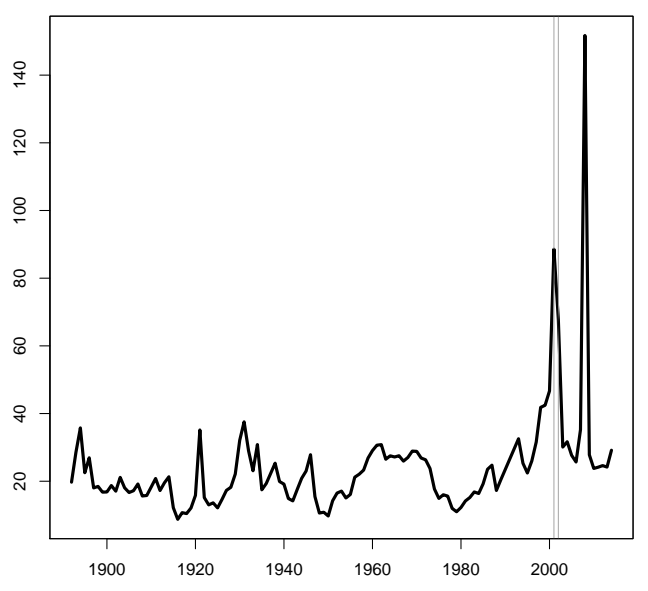

(b) $\tau_{b}=5$.

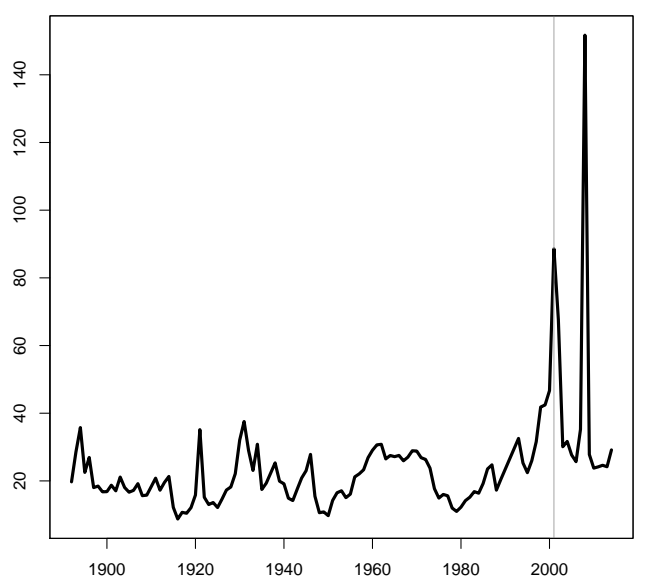

(d) $\tau_{b}=7$.

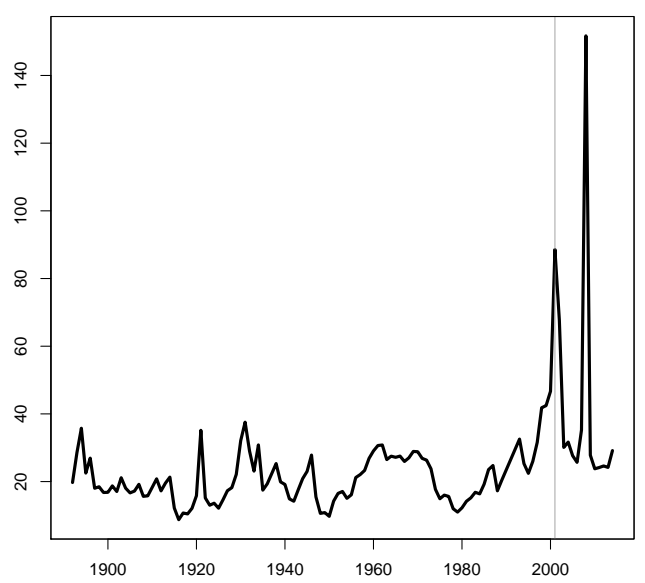

(f) $\tau_{b}=9$.

Figure 14: The figures present the trajectories of the ratio of the price and the dividend proxy MidProxies with the corresponding results of the pseudo real-time monitoring proposed by Phillips \& Shi (2020) for a significance level of $\alpha=0.05$. The size control parameter $\tau_{b}$ increases from the left upper figure to the right figure at the bottom from four to nine by steps of one. The number of lags in the Augmented Dickey Fuller regression (see Equation (7)) is selected by the $B I C$. Gray shaded areas indicate explosive periods. 


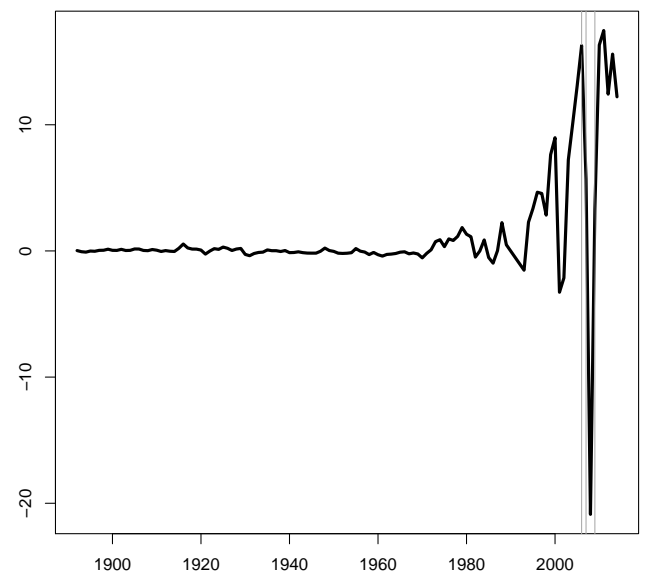

(a) HDNIX03 vs. realized dividends

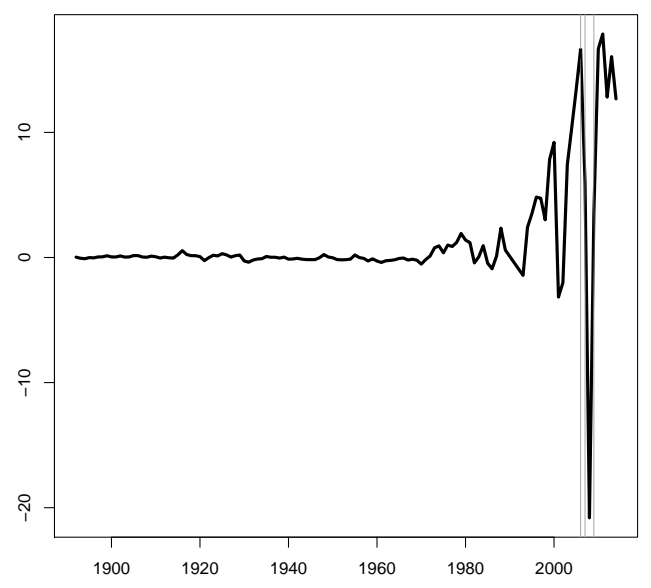

(c) HDWW2 vs. realized dividends

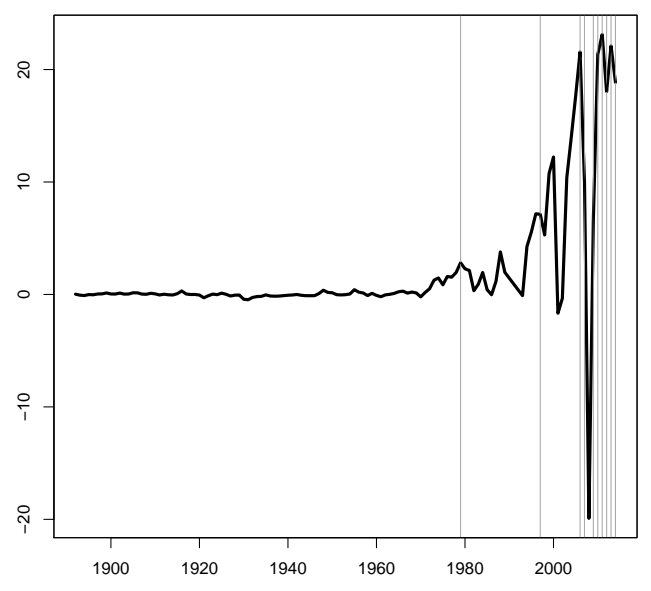

(b) HDWW1 vs. realized dividends

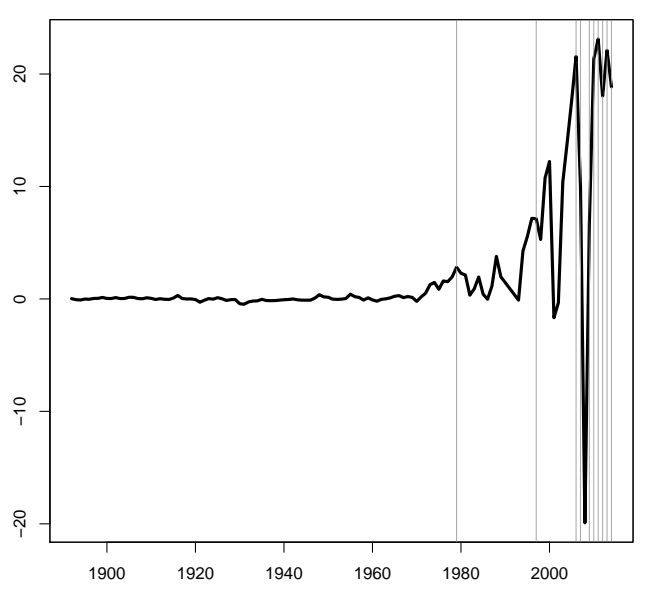

(d) HDBW vs. realized dividends

Figure 15: The figures present the trajectories of series constructed as the difference between selected hypothetical dividends and realized dividends with the corresponding results of the pseudo real-time monitoring proposed by Phillips \& Shi (2020) for a significance level of $\alpha=0.05$. The size control parameter $\tau_{b}$ is set to 7 in all cases. The number of lags in the Augmented Dickey Fuller regression (see Equation (7) ) is selected by the $B I C$. Gray shaded areas indicate explosive periods. 